
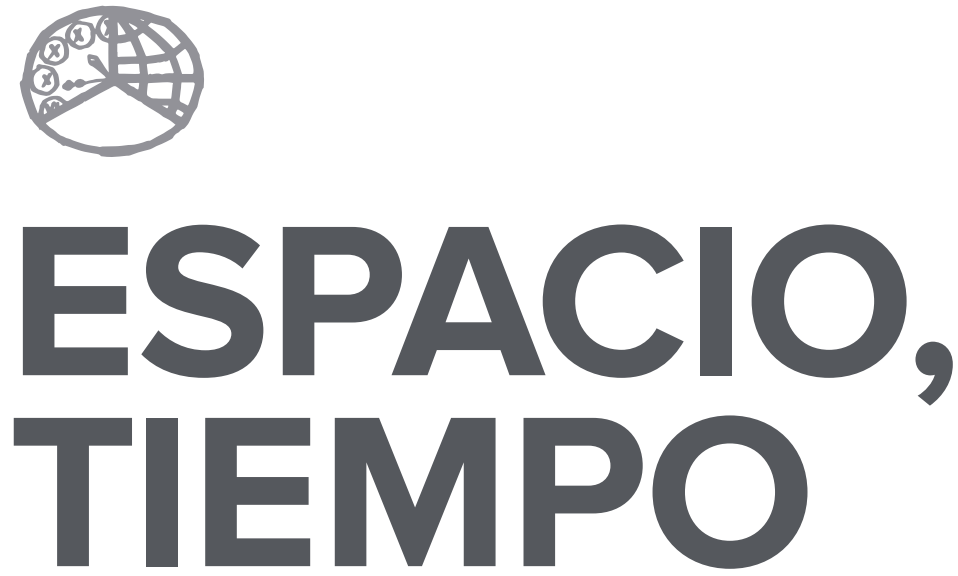

AÑO 2016

ISSN 0214-9745

E-ISSN 2340-1362
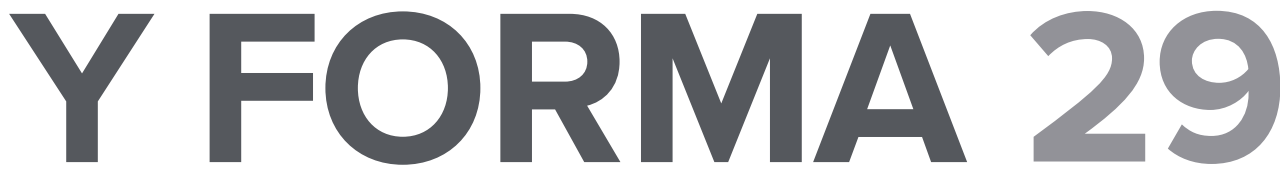

SERIE III HISTORIA MEDIEVAL

REVISTA DE LA FACULTAD DE GEOGRAFÍA E HISTORIA 


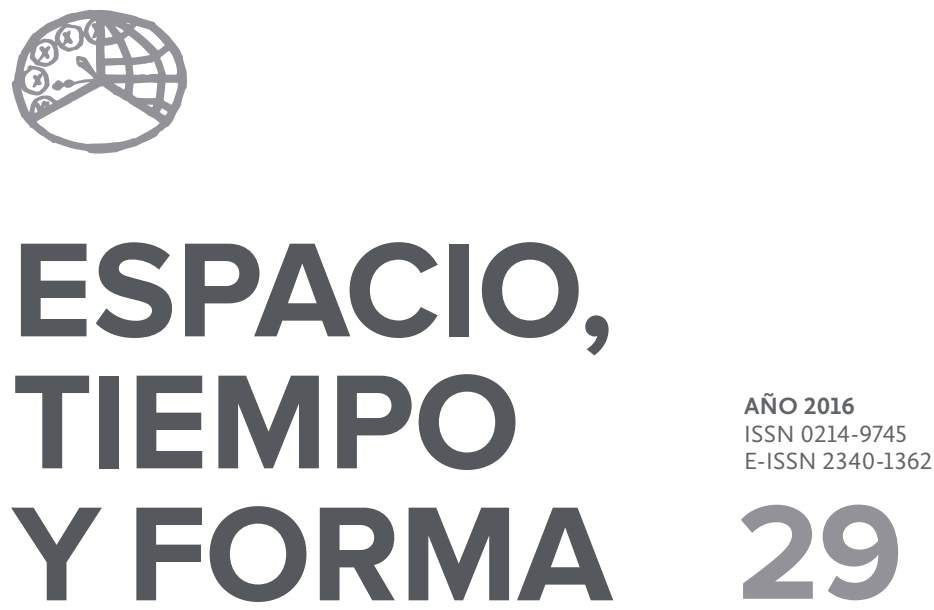

SERIE III HISTORIA MEDIEVAL

REVISTA DE LA FACULTAD DE GEOGRAFÍA E HISTORIA

http://dx.doi.org/10.5944/etfiii.29.2016

\section{UกED}

UNIVERSIDAD NACIONAL DE EDUCACIÓN A DISTANCIA 
La revista Espacio, Tiempo y Forma (siglas recomendadas: ETF),

de la Facultad de Geografía e Historia de la UNED, que inició su publicación el año 1988, está organizada de la siguiente forma:

$$
\begin{aligned}
& \text { SERIE I - Prehistoria y Arqueología } \\
& \text { SERIE II - Historia Antigua } \\
& \text { SERIE III - Historia Medieval } \\
& \text { SERIE IV - Historia Moderna } \\
& \text { SERIE V - Historia Contemporánea } \\
& \text { SERIE VI - Geografía } \\
& \text { SERIE VII - Historia del Arte }
\end{aligned}
$$

Excepcionalmente, algunos volúmenes del año 1988 atienden a la siguiente numeración:
N. ${ }^{\circ} 1$ - Historia Contemporánea
N. ${ }^{\circ} 2-$ Historia del Arte
N. ${ }^{\circ} 3-$ Geografía
N. ${ }^{\circ} 4 \quad-$ Historia Moderna

ETF no se solidariza necesariamente con las opiniones expresadas por los autores.

UNIVERSIDAD NACIONAL DE EDUCACIÓN A DISTANCIA

Madrid, 2016

SERIE III - HISTORIA MEDIEVAL N. ${ }^{\circ} 29,2016$

ISSN 0214-9745 · E-ISSN 2340-1362

DEPÓSITO LEGAL M-21037-1988

URL: ETF III - HISTORIA MEDIEVAL · http://revistas.uned.es/index.php/ETFIII

DISEÑO Y COMPOSICIÓN

Carmen Chincoa Gallardo · http://www.laurisilva.net/cch

Impreso en España · Printed in Spain 


\section{ARTÍCULOS}





\title{
LA RENTA SEÑORIAL DE LA \\ ORDEN DE SAN JUAN EN CASTILLA \\ DURANTE LOS SIGLOS XII Y XIII
}

\section{RENTS FROM THE LORDSHIPS OF THE ORDER OF SAINT JOHN IN CASTILE DURING THE TWELFTH AND THIRTEENTH CENTURIES}

\section{Carlos Barquero Goñi ${ }^{1}$}

Recepción: 2015/9/3 . Comunicación de observaciones de evaluadores: 2015/11/13 .

Aceptación: 2016/1/7

DOI: http://dx.doi.org/10.5944/etfiii.29.2016.16745

\section{Resumen}

La Orden de San Juan obtuvo muchos recursos de sus dominios en Castilla durante los siglos XII y XIII. Sus fuentes de renta eran las contribuciones habituales en el régimen señorial durante la Edad Media. Sin embargo, el principal ingreso era una parte del diezmo eclesiástico que la Orden percibía en sus señoríos.

\section{Palabras clave}

Renta; señorío; Órdenes Militares; Orden de San Juan; Castilla; Edad Media; economía; sociedad.

\begin{abstract}
The Order of Saint John collected significant resources from their domains in Castile during the twelfth and thirteenth centuries. Their sources of income were the usual contributions of the manorial system during the Middle Ages. Nevertheless, their main source of income was a fraction of the ecclesiastical tithe that the order perceived in their lordships.
\end{abstract}

Keywords

Rent; Lordship; Military Orders; Order of Saint John; Castile; Middle Ages; Economy; Society. 


\section{INTRODUCCIÓN: LA RENTA SEÑORIAL O FEUDAL Y LAS ÓRDENES MILITARES²}

Consideramos que es necesario prestar atención al problema de las rentas que la Orden de San Juan o del Hospital obtenía de sus dominios en Castilla durante la Plena Edad Media3. La mayoría de los estudios modernos sobre señoríos medievales dedican siempre un espacio menor o mayor a la cuestión a causa de las importantes consecuencias económicas y sociales que conlleva la renta señorial o feudal ${ }^{4}$. En un nivel más genérico, el tema ha llamado la atención de autores tan diferentes como Moxó ${ }^{\text {, Moreta Velayos }}{ }^{6}$ o Alfonso Antón 7 . En el campo de las órdenes militares, el investigador quizás que ha mostrado una mayor preocupación ha sido Peinado Santaella ${ }^{8}$. Carlos de Ayala, Enrique Rodríguez-Picavea y Feliciano Novoa también han hecho aportaciones muy interesantes ${ }^{9}$. Precisamente Rodríguez-Picavea ha sido el único hasta ahora en tratar el tema de la renta feudal de la Orden de San Juan en Castilla, aunque limitado al ámbito de la frontera con el Islam ${ }^{\mathrm{Io}}$. Por lo demás, en el caso de la Orden de San Juan en el resto de la Península Ibérica la materia sólo ha sido tocada por María Bonet para el ejemplo de la encomienda hospitalaria de Ulldecona, en el Sur de Cataluña ${ }^{\text {II }}$.

2. El presente trabajo forma parte del proyecto de investigación «Génesis y desarrollo de la guerra santa cristiana en la Edad Media del Occidente Peninsular (siglos X-XIV)», financiado por el Ministerio de Economía y Competitividad (HAR2012-32790).

3. BARquero GoÑI, Carlos, Los caballeros hospitalarios durante la Edad Media en España, Burgos, La Olmeda, 2003, págs. 82-88. BARQUero GoÑI, Carlos, «Los hospitalarios en el reino de León (siglos XII y XIII)», en El reino de León en la Alta Edad Media IX, León, Centro de Estudios e Investigación San Isidoro, 1997, pp. 423-439.

4. Clemente Ramos, Julián, La economía campesina en la Corona de Castilla (1000-1300), Barcelona, Crítica, 2003, págs. 161-238.

5. Moxó, Salvador de, «Los señoríos: cuestiones metodológicas que plantea su estudio», Anuario de Historia del Derecho Español, 43 (1973), pp. 300-309. Moxó, Salvador de, «Los señoríos. Estudio metodológico», en Actas de las I Jornadas de Metodología Aplicada de las Ciencias Históricas. II Historia Medieval, Santiago de Compostela, 1975, pp. 171-173. Reeditado en Moxó, Salvador de, Feudalismo, señorío y nobleza en la Castilla medieval, Madrid, Real Academia de la Historia, 2000, págs. 131-135.

6. Moreta Velayos, Salustiano, Rentas monásticas en Castilla: problemas de método, Salamanca, Universidad de Salamanca, 1974.

7. Alfonso Antón, Isabel, «Renta señorial en la Edad Media de León y Castilla», en Historia de la Hacienda Española (épocas antigua y medieval). Homenaje al profesor García de Valdeavellano, Madrid, Instituto de Estudios Fiscales, 1982, pp. 55-65.

8. Peinado Santaella, Rafael G., «Estructura de la renta feudal en los señoríos andaluces de la Orden de Santiago a finales de la Edad Media. I Encomiendas orientales», en Actas I Coloquio de Historia de Andalucía. Andalucía Medieval, Córdoba, 1982, pp. 471-507. Peinado SANTAelLA, Rafael G., «La renta señorial en las órdenes militares de la Corona de Castilla durante la baja Edad Media», Historia, Instituciones, Documentos, 18 (1991), pp. 403-424.

9. Ayala MartíneZ, Carlos de, Las Órdenes Militares hispánicas en la Edad Media (siglos XII-XV), Madrid, Marcia Pons, 2003, págs. 637-695. RODRíGUEz-PICAVEA, Enrique, La formación del feudalismo en la meseta meridional castellana. Los señoríos de la Orden de Calatrava en los siglos XII-XIII, Madrid, Siglo XXI, 1994, págs. 333-374. Rodríguez-PICAVEA, Enrique, Los monjes guerreros en los reinos hispánicos. Las Órdenes Militares en la Península Ibérica durante la Edad Media, Madrid, La Esfera de los Libros, 2008, págs. 355-384. NOVOA PORTELA, Feliciano, La Orden de Alcántara y Extremadura (siglos XII-XIV), Mérida, Editora Regional de Extremadura, 2000, págs. 233-276.

10. Rodríguez-Picavea Matilla, Enrique, Las Órdenes Militares y la frontera. La contribución de las Órdenes a la delimitación de la jurisdicción territorial de Castilla en el siglo XII, Madrid, Universidad Autónoma de Madrid, 1994, págs. 37-78. Rodríguez-Picavea Matilla, Enrique, «La Orden de San Juan en la frontera castellano-andalusí del siglo XIl», Actas del Primer Simposio Histórico de la Orden de San Juan en España, Toledo, 2003, pp. 121-142.

11. BONET DONATO, María, «Las cartas de población y la renta feudal en el dominio hospitalario del Montsià (s. 
Nosotros no vamos exponer aquí una nueva propuesta de división de rentas, como suelen hacer la mayoría de los autores citados. Sin embargo, es un tema que nos debemos plantear, porque los mismos contemporáneos de la época de nuestro estudio sentían una vaga necesidad de diferenciar los distintos ingresos que podían obtenerse de un dominio. Un pacto de i238 entre la Orden de San Juan y el monasterio de Valparaíso sobre la aldea de El Cubo hace ya una tosca división, incluyendo en ella elementos tan diferentes como los diezmos eclesiásticos y las caloñas: «De decimis vero omnibus et foris atque de aliis reditibus et proventibus sive calumpniis et forciis ipsius aldee» ${ }^{12}$. Por tanto, hemos acudido a un esquema que ha sido ya utilizado en algunas investigaciones sobre señoríos de órdenes militares y que fue en su momento sintetizado por el profesor Ladero Quesada ${ }^{13}$. Nuestra elección tiene el inconveniente de estar pensada para una época (siglo XV) posterior a la de nuestro periodo de estudio, pero posee la inestimable ventaja de tener en cuenta las peculiaridades propias de los dominios de las órdenes militares.

Por consiguiente, a efectos expositivos vamos a agrupar las diferentes rentas de los hospitalarios castellano-leoneses en seis grandes grupos:

* Aportaciones con origen en los bienes cuya explotación directa se había reservado la Orden.

* Tributos propiamente señoriales.

* Tasas sobre el paso de mercancías.

* Contribuciones de naturaleza eclesiástica.

* Exenciones de impuestos regios y rentas inicialmente de la monarquía concedidas a la Orden.

* Ingresos procedentes del dominio sobre organismos concejiles.

Como es obvio, no contamos con suficiente información cuantificable como para hallar las cifras absolutas totales que correspondían a cada partida. Carecemos para esta época de los libros de visitas que tan excelentemente han sido explotados con este fin en los estudios sobre órdenes militares peninsulares durante el siglo $\mathrm{XV}^{\mathrm{I} 4}$. En el Hospital también se realizaban visitas. Una de las primeras que se conservan es la que se verificó en el priorato de Saint Gilles en I338, estudiada por

\footnotetext{
XIII)», en Miscel.lània en homenatge al P. Agustí Altisent, Tarragona, Diputación de Tarragona, 1991, pp. 551-571.

12. LeRA Maíllo, José Carlos de y otros, Colección diplomática del imperial monasterio de Nuestra Señora de Valparaíso (1143-1499), Zamora, Instituto de Estudios Zamoranos Florián de Ocampo, 1998, págs. 57-60, n 53.

13. Ladero Quesada, Miguel Ángel, «Comentario sobre los señoríos de las órdenes militares de Santiago y Calatrava en Castilla la Nueva y Extremadura a fines de la época medieval», Las órdenes militares en el Mediterráneo occidental. Siglos XIII-XVIII, Madrid, 1989, pp. 176-177.

14. Solano, Emma, La Orden de Calatrava en el siglo XV. Los señoríos castellanos de la Orden al fin de la Edad Media, Sevilla, Universidad de Sevilla, 1978. Porras ArboledAS, Pedro Andrés, Los señoríos de la Orden de Santiago en su provincia de Castilla durante el siglo XV, Madrid, Universidad Complutense, 1981, 2 volúmenes. PorRAS ARBOLEDAS, Pedro Andrés, La Orden de Santiago en el siglo XV. La provincia de Castilla, Madrid, Dykinson, 1997. RodríGUez BLANCo, Daniel, La Orden de Santiago en Extremadura en la Baja Edad Media (siglos XIV y XV), Badajoz, Diputación Provincial de Badajoz, 1985.
} 
el conocido medievalista francés Georges Duby ${ }^{15}$. Desgraciadamente, las visitas del priorato de Castilla y León que hemos podido conocer en el Archivo Histórico Nacional y en el Archivo General del Palacio Real de Madrid son bastante más tardías y se ubican ya plenamente en la Edad Moderna. Por consiguiente, en las siguientes líneas sólo vamos a poder hacer una aproximación cualitativa, no cuantitativa, al tema con los datos que nos ofrecen los diplomas.

\section{BIENES EXPLOTADOS DIRECTAMENTE POR LA ORDEN.}

Los freires sanjuanistas contaban con diversas propiedades ubicadas en el interior de poblaciones de su señorío. Concretamente, son frecuentes las alusiones a la presencia de una «casa de la Orden» o «del Hospital» en varias localidades, curiosamente siempre al Sur del Duero. Es el caso de Peñalver hacia $\mathrm{II}_{6} \mathrm{O}^{\mathrm{I} 6}$ y en $\mathrm{I} 334^{\mathrm{I7}}$, Alhóndiga en $\mathrm{II} 7 \mathrm{O}^{\mathrm{I}}$, Cedillo del Condado en $\mathrm{I} 2 \mathrm{I}^{\mathrm{I9}}$, Villacañas en $\mathrm{I}_{23 \mathrm{O}^{20}}$, Villamiel en $\mathrm{I} 235^{2 \mathrm{I}}$, Alcázar de San Juan en $\mathrm{I} 24 \mathrm{I}^{22}$ y en $\mathrm{I} 308^{23}$, Villacañas de Algodor en $1248^{24}$, Villaverde en ese mismo año ${ }^{25}$ y Fresno el Viejo en $1286^{26}$. Seguramente desde estos inmuebles se administrarían las otras propiedades sanjuanistas situadas en cada población.

Entre ellas destacan especialmente las «sernas». La documentación hospitalaria utiliza este término mayoritariamente en el sentido de tierra sembrada de cereal $^{27}$. Tan sólo una vez, en Fresno el Viejo, la palabra tiene el conocido significado de prestación en trabajo ${ }^{28}$. Llama la atención el hecho de que las sernas de la Orden sean citadas por regla general en las cartas de población otorgadas por el comendador de Consuegra en la Mancha. Es el caso de Turleque, Tembleque,

15. DuBY, Georges, «El señorío y la economía campesina. Alpes del Sur, 1338», en DuBY, Georges, Hombres y estructuras de la Edad Media, Madrid, Siglo XXI, 1977, págs. 79-119. Véase también CouLET, Nicolas, «Les Ordres militaires, la vie rurale et le peuplement dans le sud-est de la France au Moyen Age», Les Ordres militaires, la vie rurale et le peuplement en Europe occidentale (XIle-XVIII siècles), Auch, 1986, pp. 48-53.

16. Ayala Martínez, Carlos de (Compilador), Libro de privilegios de la Orden de San Juan de Jerusalén en Castillay León (siglos XII-XV), Madrid, Editorial Complutense, 1995, págs. 237-239, nº 77.

17. Calderón Ortega, José Manuel, «Ordenanzas municipales de la villa de Peñalver», Anuario de Estudios Medievales, 18 (1988), p. 327.

18. Catalina García, Juan, «Carta-puebla de Alhóndiga», Boletín de la Real Academia de la Historia, 35 (1899), p. 474.

19. Ayala Martínez, C., Libro de privilegios..., págs. 402-403, $n^{\circ} 218$.

20. AguirRe, Domingo, El gran priorato de San Juan de Jerusalén en Consuegra, en 1769, Toledo, Instituto Provincial de Investigaciones y Estudios Toledanos, 1973, págs. 121-122.

21. Ayala Martínez, C., Libro de privilegios..., págs. 462-463, nº 264.

22. Archivo General de Palacio, Sección Infante don Gabriel, Anexo, legajo 1, nº 22.

23. Rubio Herguido, Manuel, «Privilegio otorgado por Frey Arias Gutiérrez Quijada. Año 1308», Noria. Cuadernos de temas alcazareños, 2 (1963), p. 20.

24. BARQuero GoÑI, Carlos, «Aportación al estudio de la repoblación sanjuanista en la Mancha», Repoblación y reconquista. Actas del III Curso de Cultura Medieval, Aguilar de Campoo, 1993, p. 174, Documento 1.

25. Idem, p. 174, Documento 2.

26. Ayala Martínez, C., Libro de privilegios..., págs. 608-611, nº 380 .

27. Alfonso de Saldaña, María Isabel, «Las sernas en León y Castilla», Moneda y Crédito, 129 (1974), p. 158.

28. Ayala Martínez, C., Libro de privilegios..., págs. 608-611, nº 380. 
Arenas de San Juan y Villaverde ${ }^{29}$. Se detecta otra más en Alcázar de San Juan en I30 $8^{30}$. Además, sabemos que durante el siglo XVIII el Prior de la Orden continuaba teniendo campos de cereal (que se seguían llamando sernas) en casi todas las villas sanjuanistas de esta misma región ${ }^{31}$. Da la impresión de que los hospitalarios se reservaron grandes extensiones para el cultivo del cereal bajo su explotación directa en el momento mismo de la repoblación de las tierras manchegas.

Otra clase de propiedad rústica que frecuentemente aparece ligada a los freires sanjuanistas en sus señoríos la constituían los prados y dehesas para el ganado. El fenómeno lo constatamos en primer lugar en la Mancha. Ya en I2I5 se constituyeron cuatro grandes dehesas en torno a los castillos hospitalarios de Peñarroya, la Ruidera, Campo de Santa María y Villacentenos por concesión real ${ }^{32}$. Posteriormente los acuerdos con las órdenes de Calatrava y de Santiago en I232 y I237 muestran la frecuente presencia de dehesas del Hospital en la zona33. Los freires sanjuanistas disponían de prados en Humanes de Madrid durante el siglo XIII ${ }^{34}$. También en Villamiel había prados de la Orden en I2355. Ese mismo año se cita la existencia de una dehesa sanjuanista, la de Cañizal, en el valle del Guareña ${ }^{36}$. Hasta I254 el Hospital tuvo un prado en Peñalver ${ }^{37}$. También la Orden retuvo para sí todas las dehesas del término de Lora del Río menos una en el momento de la emisión de su carta de población en I259 $9^{38}$. En Alcázar de San Juan había otra dehesa sanjuanista «de los nuestros buyes» en $1308^{39}$. Todas estas referencias, bastante numerosas, parecen sugerir que la ganadería era una de las principales dedicaciones de las propiedades de la Orden situadas en el interior de sus señoríos. Sería una característica que cuadraría bastante bien con los conocimientos actuales sobre la elevada importancia del capítulo ganadero en la economía de las órdenes militares en España durante la época de nuestro estudio ${ }^{40}$.

\footnotetext{
29. Aguirre, D., El gran priorato..., págs. 113, 117, 138. BARQuero GoÑI, C., Aportación al estudio de la repoblación..., p. 174 .

30. Rubio Herguido, M., Privilegio..., p. 21.

31. AguirRe, D, El gran priorato..., págs. 98, 101, 104, 107, 110, 113, 117, 122, 125, 129, 130, 134 y 139.

32. Ayala Martínez, C. de y otros, «Algunos documentos sobre órdenes militares y fortalezas», Castellum, 1 (1992), pp. 92-93, n० 4 .

33. Ortega y Cotes, Ignacio José, Álvarez de Baquedano, Juan Francisco, y Ortega Zúñiga y Aranda, Pedro de, Bullarium Ordinis Militiae de Calatrava, Barcelona, El Albir, 1981, pág. 65. LomAX, Derek W., La Orden de Santiago (1170-1275), Madrid, CSIC, 1965, págs. 259-260.

34. Ayala martínez, C., Libro de privilegios..., pág. 384, nº 200 y págs. 543-544, nº 330.

35. Ayala Martínez, C., Libro de privilegios..., págs. 462-463, $n^{\circ} 264$.

36. González, Julio, Reinado y diplomas de Fernando III, Córdoba, Caja de Ahorros de Córdoba, 1980-1986, volumen III, págs. 83-84, $\mathrm{n}^{\circ} 565$.

37. Ayala Martínez, C., Libro de privilegios..., pág. 537, nº 325 .

38. González Carballo, José, «Carta-puebla de Lora del Río», Lora del Río. Revista de Estudios Locales, I (1990), p. $34, n^{\circ} 1$.

39. Rubio Herguido, M., Privilegio..., p. 21.

40. Gerbet, Marie-Claude, «Les Ordres Militaires et l'élevage dans l'Espagne médiévale», En la España Medieval V. Estudios en memoria del profesor D. Claudio Sánchez-Albornoz, Madrid, Universidad Complutense, 1986, volumen I, págs. 425-441.
} 
Probablemente este tipo de explotaciones constituirían una buena fuente de ingresos para los hospitalarios a nivel local. Sabemos que a partir de I2I5 cada rebaño de ovejas que penetrase en las dehesas de los castillos sanjuanistas de Peñarroya, la Ruidera, Campo de Santa María y Villacentenos debía entregar cinco carneros. Si fuera de ganado bovino, pagaría una vaca ${ }^{41}$. Años más tarde, en I272, los freires sanjuanistas cobraban un sueldo por cada cabeza de ganado mayor que entraba en sus dehesas de Peñalver y seis dineros por cada ejemplar de ganado menor ${ }^{42}$.

La tercera dedicación más importante de las tierras directamente explotadas por la Orden en sus villas debían de ser los viñedos. Las referencias documentales son relativamente frecuentes. En concreto, encontramos constancia de viñas del Hospital durante la época objeto nuestro estudio en Alhóndiga ${ }^{43}$, Olmos ${ }^{44}$, Turleque $^{45}$, Peñalver ${ }^{46}$, Villacentenos y Cervera ${ }^{47}$.

Los textos nos proporcionan referencias de algunas propiedades de tipos diferentes a los ya señalados. En Alhóndiga el Hospital tenía huertos y heredades en $\mathrm{II}_{7 \mathrm{O}^{48}}$. En Villamiel había huertos y árboles pertenecientes a los freires en $1235^{49}$. Las ordenanzas de Peñalver del año I334 también citan a las huertas y «arbores» de la Orden ${ }^{50}$. Muy interesante es el caso de Villacentenos y Cervera, dos lugares que fueron concedidos por el gran comendador de España en I292 a Alcázar de San Juan. Con ese motivo se hizo relación de las propiedades que los freires sanjuanistas retuvieron en ellos: un cortijo, una huerta y una heredad para seis yuntas de bueyes en Villacentenos (aparte de una viña), y otra heredad para cuatro yuntas de bueyes, una huerta y unos molinos (además también de otra viña) en Cervera ${ }^{5 \mathrm{I}}$. Finalmente, los hospitalarios tenían en Fresno el Viejo un molino ${ }^{52}$ y unas heredades que debían de ser aradas mediante la prestación anual de un día de trabajo para la Orden a la que estaba obligado todo poblador que dispusiera de bueyes ${ }^{53}$.

Las evidencias recogidas nos demuestran la pervivencia de un dominio directo o, por utilizar un vocablo del régimen señorial clásico, de una «reserva» de cierta magnitud en los señoríos hospitalarios a lo largo de los siglos XIl y XIII.

Por otra parte, es evidente que los freires sanjuanistas poseían numerosas propiedades en zonas fuera de los límites de sus señoríos. Algunas de ellas eran cultivadas a expensas de los propios freires. Así se dice explícitamente que ocurría

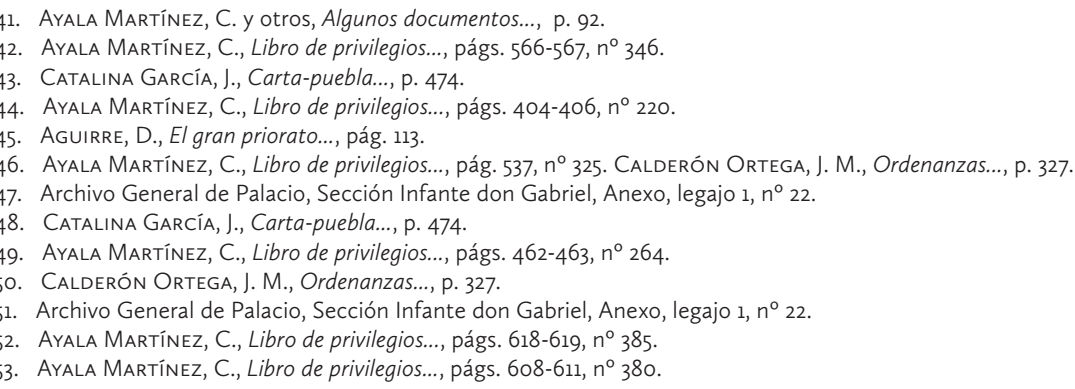


con ciertas tierras de Peñaserrín y Moreras en i266, por sólo citar un ejemplo que nos ha parecido significativo ${ }^{54}$. Sin embargo, da la impresión de que buena parte de estos bienes eran explotados por la Orden de forma indirecta. Existen algunos testimonios que así lo indican. Las frecuentes cesiones de propiedades sanjuanistas en tenencia vitalicia a personajes poderosos para incentivar la donación subsiguiente de otros bienes puede interpretarse como un fácil expediente que solucionaba el problema de su administración y gestión, y que proporcionaba un rendimiento seguro a largo plazo 55 .

También perviven otras manifestaciones de explotación indirecta quizá más evidentes. En I282 las casas que tenía en la ciudad de Zamora la bailía de Santa María de la Horta estaban alquiladas para poder pagar con sus rentas los emolumentos del freire rector de dicha iglesia ${ }^{56}$. Los arrendamientos debían de ser frecuentes. Contamos con dos buenos ejemplos de ello. El prior del Hospital repartió la viña que la Orden poseía en Cadalso de los Vidrios entre varios pobladores en I272. Cada una de las porciones en que fue dividida estaba gravada con un censo anual de dos maravedís ${ }^{57}$. Ya fuera de los límites cronológicos de nuestro estudio, sabemos que durante los primeros años del siglo XIV prácticamente todas las tierras propiedad de los freires sanjuanistas en la huerta de Murcia estaban arrendadas ${ }^{58}$.

\section{TRIBUTOS PROPIAMENTE SEÑORIALES.}

A continuación, vamos a pasar a analizar aquellos derechos que se derivaban más directamente del poder señorial. Continuando con el esquema del profesor Ladero, realizaremos una nueva subdivisión de este tipo de contribuciones en tres grandes grupos: ingresos derivados de la administración de justicia, monopolios y rentas procedentes del reconocimiento del señorío de la Orden por parte de los pobladores de cada lugar 59 .

Como en casi todos los grandes dominios de la época, los hospitalarios disfrutaban de facultades judiciales sobre el suyo. De ahí que frecuentemente tuvieran una participación en los ingresos que se derivaban del ejercicio de esta potestad: las caloñas o multas. En un sistema judicial como el medieval en el que la mayoría

54. Martín Martín, José Luis y otros, Documentos de los Archivos Catedralicio y Diocesano de Salamanca (siglos XII-XIII), Salamanca, Universidad de Salamanca, 1977, págs. 406-407, $n^{\circ} 314$.

55. Archivo Histórico Nacional, Sección Órdenes Militares, carpeta 575, $n^{\circ} 33$ y $n^{\circ} 34$.

56. Ramos de CASTRO, Guadalupe, El arte románico en la provincia de Zamora, Zamora, Diputación de Zamora, 1977, págs. 525-526.

57. Ayala Martínez, C., Libro de privilegios..., págs. 567-568, nº 347.

58. Serra Ruiz, Rafael, «La Orden de San Juan de Jerusalén en el reino de Murcia (siglo XIII)», Anuario de Historia del Derecho Español, 38 (1968), pp. 586-590, n XII. Véase también Archivo Histórico Nacional, Sección Órdenes Militares, Índice 175 , folio 114 recto, $\mathrm{n}^{\circ} 4$.

59. Ladero Quesada, Miguel Ángel, «Comentario sobre los señoríos de las órdenes militares de Santiago y Calatrava en Castilla la Nueva y Extremadura a fines de la época medieval», en Las órdenes militares en el Mediterráneo occidental. Siglos XIII-XVIII, Madrid, Instituto de Estudios Manchegos, 1989, p. 176. 
de las penas eran pecuniarias, las cantidades recibidas por dicha vía podían ser apreciables.

Al principio, el porcentaje reservado a los freires sanjuanistas era minoritario. El fuero de Atapuerca en II38 preveía que sólo la cuarta parte de las caloñas fueran a parar al Hospital ${ }^{60}$. Sin embargo, muy pronto comenzó a producirse una tendencia alcista en la participación sanjuanista. Ya alcanzaba la tercera parte en Alhóndiga según preveía la carta de $1170^{61}$. Idéntica proporción fue implantada en Humanes de Madrid a partir de $1222^{62}$. Todavía mayor fue la que obtuvo la Orden en el fuero de Trevejo de I228: nada menos que la mitad de las caloñas por delitos cometidos en dicha localidad o en su término sería para el Hospital, y en el caso de las multas por hurto los freires sanjuanistas recaudarían todo lo que produjeran ${ }^{63}$. En la vecina Villamiel su carta de población de I235 también regulaba que la mitad de las caloñas fueran cobradas por los hospitalarios ${ }^{64}$. Asimismo, el prior de la Orden de San Juan solía recibir una participación del 50\% en las multas derivadas de la actividad de los dos jueces establecidos por el rey en Consuegra ${ }^{65}$.

En la segunda mitad del siglo XIII el porcentaje correspondiente al Hospital es ya mayoritario y a veces alcanza el Ioo\%. Un ejemplo elocuente es el fuero breve otorgado a Peñalver en I272, en el que todos los pechos y caloñas derivados de los juicios debían de ser entregados al comendador sanjuanista que tuviera la bailía ${ }^{66}$. A partir de la cesión de Cubillas de Duero al Hospital en I28I también aquí todas las penas pecuniarias serían para la Orden ${ }^{67}$. En cambio, el acuerdo de 1286 con el concejo de Fresno el Viejo contenía que los freires sanjuanistas percibirían dos terceras partes de las caloñas de los pleitos criminales ${ }^{68}$.

En definitiva, nuestras fuentes evidencian un crecimiento sostenido del interés sanjuanista por las rentas vinculadas a la administración de justicia.

La presencia de monopolios era otro rasgo fundamental del régimen señorial vigente en los dominios castellanos de la Orden de San Juan. El que encontramos documentado con más frecuencia es el del horno. Se trataba de un elemento vital en el seno de una economía dominada por el cultivo de cereales panificables. Durante la segunda mitad del siglo XII la presencia de este monopolio se evidencia en Peñalver y Alhóndiga. En ambos casos tenía capacidad para 30 panes. No podía existir ningún otro similar en la localidad. Tan sólo se permitiría que cada habitante hiciera su propio horno cuando el de la Orden estuviera estropeado. El

6o. Martínez Díez, Gonzalo, Fueros locales en el territorio de la provincia de Burgos, Burgos, Institución Fernán González, 1982, pág. 148

61. Catalina García, Juan, «Carta-puebla de Alhóndiga», Boletín de la Real Academia de la Historia, 35 (1899), p. 474

62. Ayala Martínez, C., Libro de privilegios..., págs. 425-426, n² 237.

63. Ayala martínez, C., Libro de privilegios..., págs. 439-441, $n^{\circ} 248$.

64. Ayala Martínez, C., Libro de privilegios..., págs. 462-463, $n^{\circ} 264$.

65. Ayala Martínez, C., Libro de privilegios..., págs. 528-529, n³ 317.

66. Ayala Martínez, C., Libro de privilegios..., págs. 566-567, nº 346.

67. Ayala Martínez, C., Libro de privilegios..., págs. 574-575, nº 353.

68. Ayala Martínez, C., Libro de privilegios..., págs. 608-611, nº 380. 
Hospital era responsable de que su horno no dañase el pan de los pobladores ${ }^{69}$. En Humanes de Madrid también debía de constituir un monopolio del señorío sanjuanista, ya que parece darlo por sobreentendido una cláusula del fuero breve otorgado por la Orden al lugar a comienzos del siglo XIll que prescribía al respecto del horno que los freires no dañasen los panes de los vecinos ni les provocaran ninguna otra contrariedad, y que cocieran su pan si fuera necesario los jueves ${ }^{70}$.

El régimen monopolístico del horno tendió a atenuarse durante la decimotercera centuria. Por lo menos así lo sugiere el sistema que está presente en todas las cartas de población concedidas por el Hospital en la Mancha con la única excepción de la de Villacañas. Consistía en que la Orden debía mantener en la localidad un horno con capacidad para treinta panes, pero cada uno de los habitantes podría tener su propio horno en su casa para su exclusivo uso personal. Lo que sí quedaba severamente penalizado era que lo utilizara otra persona aparte del dueño. Las referidas condiciones fueron implantadas entre los años I236 y I248 en Arenas de San Juan, Madridejos, Camuñas, Herencia, Tembleque, Quero, Alcázar de San Juan, Turleque, Villacañas de Algodor y Villaverde ${ }^{71}$.

La conclusión lógica del proceso era la desaparición del monopolio señorial del horno. Sabemos que así ocurrió por lo menos en un caso durante la primera mitad del siglo XIV. En Peñalver, donde ya hemos comprobado que el citado monopolio existía desde el siglo XII, el Concejo consiguió en I334 que la Orden le entregara su horno y que los habitantes pudieran hacer otros en sus casas a condición de pagar anualmente I.500 maravedís al comendador de Peñalver en la fiesta de San Miguel $^{72}$. No sabemos si ocurrió lo mismo en otras villas sanjuanistas, pero es verosímil que así sucediera, puesto que la tendencia reseñada durante el siglo XIII apuntaba hacia ello. De esta forma, la importancia del monopolio del horno en el conjunto de las rentas señoriales del Hospital habría sufrido un descenso continuado a lo largo de todo el periodo de nuestro estudio, justo lo contrario de lo que hemos visto suceder con los ingresos procedentes de las caloñas.

También existieron otros tipos diferentes de monopolios en los dominios sanjuanistas. Quizá podamos considerar como uno de ellos, constatado durante el siglo XII, el «derecho de relego» o derecho exclusivo que tenía el Hospital a vender vino en Peñalver durante el mes de abril o el de mayo, el que más prefiriera de los dos. Sólo con el permiso del comendador podría vender vino otra persona en ese plazo $^{73}$.

69. Ayala Martínez, C., Libro de privilegios..., págs. 236-237, nº 76. Catalina García, J., Carta-puebla de Alhóndiga..., p. 473.

70. Ayala martínez, C., Libro de privilegios..., pág. 384, nº 200.

71. Aguirre, D., El gran priorato..., págs. 96, 100, 103, 112, 115, 124, 128 y 138. BARQUero GoÑI, C., Aportación al estudio de la repoblación..., p. 174.

72. Calderón Ortega, José Manuel, «Ordenanzas municipales de la villa de Peñalver», Anuario de Estudios Medievales, 18 (1988), pp. 326-327.

73. Ayala Martínez, C., Libro de privilegios..., págs. 237-239, nº 77. 
Hay ciertas actividades que, sin ser monopolios propiamente dichos, sí estaban sujetas a una autorización previa de la Orden, obtenible sólo mediante el pago de una renta. Por consiguiente, en la práctica las podemos considerar como monopolios suavizados. El resultado para los hospitalarios era el mismo, puesto que conseguían así una fuente de ingresos constante. Da la impresión de que la explotación de molinos hidráulicos en el interior de territorios sanjuanistas era una de estas actividades. Al parecer, era necesaria una concesión previa de los hospitalarios para su establecimiento, quienes sólo la facilitaban a cambio de una renta. Contamos con tres ejemplos muy ilustrativos de ello, localizados todos en el territorio al norte de Toledo.

El primer caso data del año II85. Entonces el prior del Hospital dio su autorización a once habitantes de la aldea de Villamiel de Toledo para que construyeran un molino con la condición de que la mitad de la renta que produjera fuera para la Orden ${ }^{74}$. Más adelante sabemos que en I243 el gran comendador de España permitió que unos hombres de Illescas explotaran molinos en el río Guadarrama junto a Olmos a cambio de cobrar una fanega de trigo y otra de cebada por cada cuarto de molienda. El pago debía verificarse en el castillo de Olmos una vez al año, el día 26 de diciembre. Además, la Orden gozaría de un turno de molienda gratuito en cada uno de los molinos. Aparte de todo esto, los molineros debían dar dos maravedís y un carnero a la fortaleza sanjuanista de Olmos cada año ${ }^{75}$. Muy cerca de allí, en Alconchel $7^{76}$, el prior del Hospital otorgó unos molinos llamados «de la Torrecilla» a las personas que ya los poseían de hecho en el año i254. Parece que una vez más se pone aquí de manifiesto la necesidad de una concesión formal de la Orden a pesar de que la actividad sancionada ya se estuviera desarrollando en la práctica. Por supuesto, los hospitalarios obtuvieron un beneficio: se impuso la obligación de proporcionar a la Orden de San Juan tres turnos gratuitos de molienda cada semana, y además el uso exclusivo de los aparatos durante el sábado por la noche y todo el día y la noche del domingo ${ }^{77}$.

Otra actividad sobre la cual la Orden ejercía un control riguroso era la cinegética. Lo constatamos claramente a través de los casos de Consuegra y Lora del Río. De su análisis parece desprenderse que para practicar la caza era precisa la autorización del Hospital, que la concedía a cambio del pago de un censo. Muy probablemente se tratase de un primitivo monopolio de la Orden. En I259 el comendador mayor de España estableció a través de la carta de población de Lora del Río que quien viniera a cazar en el término territorial que los freires sanjuanistas poseían entre Córdoba y Sevilla habría de abonar un sexto y un diezmo a

74. Ayala Martínez, C., Libro de privilegios..., págs. 337-338, nº 155.

75. Ayala Martínez, C., Libro de privilegios..., págs. 493-494, nº 288.

76. En la actualidad es un despoblado en el término de Palomeque (Toledo). Véase Martínez Díez, Gonzalo, «Estructura administrativa local en el naciente reino de Toledo», Estudios sobre Alfonso VI y la reconquista de Toledo. Actas del II Congreso Internacional de Estudios Mozárabes, Toledo, 1988, p. 95.

77. Ayala Martínez, C., Libro de privilegios..., págs. 538-539, nº 326. 
la Orden del Hospital ${ }^{78}$. Esta normativa sufrió una modificación parcial en el año I297 cuando el prior sanjuanista concedió especiales libertades para la práctica de la caza a los vecinos de Lora ${ }^{79}$. En concreto parece que les permitió poner trampas para coger pequeños animales con la condición de que pagaran diez maravedís a la Orden por cada puesto de cazador ${ }^{80}$.

En Consuegra también detectamos un control parecido del Hospital sobre sobre esta actividad. Hasta I289 parece que los cazadores de la villa gozaron de un privilegio especialmente ventajoso de la Orden, pero fue derogado en dicho año por petición del Concejo. A partir de entonces quienes utilizaran trampas habrían de abonar a los freires io maravedís por cada puesto, exactamente la misma tasa establecida en Lora desde I297. Por su parte, los que cazaran con perros o hurones darían a la Orden de San Juan siete maravedís todos los años por Carnaval. Además, el Hospital impuso un periodo de veda que se extendería durante prácticamente todo el invierno, concretamente desde el día de San Martín (II de noviembre) hasta el domingo de $\operatorname{Ramos}^{8 \mathrm{I}}$.

Los ingresos que la Orden cobraba en reconocimiento de su señorío sobre un determinado lugar podían ser muy variados. Un ejemplo especialmente significativo es el de Fresno el Viejo donde en 1286 coexistían cargas tan diferentes como martiniega, acémilas, fumazga, yantar y sernas ${ }^{82}$. Sin embargo, el tributo más frecuente y que casi nunca falta es la renta que cada habitante de una población bajo el señorío sanjuanista pagaba a los hospitalarios por el disfrute de sus tierras. La designación con la que más frecuentemente aparece en la documentación es la de «forum» o «foro», y a veces también «aloxor» $\mathrm{y}$ «pecho».

Por regla general se trata de un tributo que suele cobrarse en metálico. El fuero de Atapuerca de II38, que nos proporciona los datos más antiguos, nos informa de que cada casato o siervo rural pagaba anualmente dos sueldos en el día de San Miguel (29 de septiembre), la viuda que tuviera allí una heredad abonaba un sueldo y otro el mancipium o siervo personal ${ }^{83}$. Ya en la segunda mitad del siglo XII, los fueros de Peñalver y de Alhóndiga contenían disposiciones sobre el tema muy parecidas entre sí. Según ambos textos cada uno de los vecinos daría un mencal en el día de San Miguel. En cambio, tan sólo pagarían la mitad de dicha suma los atemplantes o pobladores que todavía no contaban con el suficiente tiempo de residencia en el lugar como para ser considerados vecinos. La normativa de

78. González Carballo, José, «Carta-puebla de Lora del Río», Lora del Río. Revista de Estudios Locales, I (1990), p. $34, \mathrm{n}^{\circ} 1$.

79. González Carballo, J., Carta-puebla de Lora..., p. 20.

80. Archivo General de Palacio, Infante don Gabriel, Anexo, legajo 3, Manifiesto jurídico en que la Religión de San Juan defiende su señorío territorial y de solariego en su villa y Bailiaje de Lora.

81. Ayala Martínez, C., Libro de privilegios..., págs. $623-624, n^{\circ} 389$.

82. Ayala Martínez, C., Libro de privilegios..., págs. 608-613, nº 380.

83. Martínez Díez, Gonzalo, Fueros locales en el territorio de la provincia de Burgos, Burgos, Institución Fernán González, 1982, pág. 148. 
Alhóndiga añadía que quedaba exento quien fuera hortelano de otra persona, o molinero, o yuguero ${ }^{84}$.

El fuero otorgado a la parte de Portomarín que pertenecía al Hospital en I2I2 también menciona en uno de sus artículos un tributo que debía de ser satisfecho en la fiesta de San Miguel llamado cabanage. Había además la obligación de pagar anualmente 80 sueldos cuando los «burgueses» de Portomarín quisieran acudir al capítulo de la Orden ${ }^{85}$. Pocos años después, en I228, otra normativa foral fijaba imposiciones en metálico a los habitantes de Trevejo. Eran abonadas al Hospital durante el mes de enero y la tarifa aplicable variaba en función del grado de riqueza de cada individuo. El que poseyera bienes por valor de to maravedís tendría que abonar un cuarto de maravedí anual. En cambio, aquel cuya riqueza no superase los ocho maravedís pagaría la quinta parte de un maravedí ${ }^{86}$.

La serie de once cartas de población que la Orden de San Juan emitió entre los años I230 y I248 en su señorío de la Mancha contiene datos muy similares sobre las cargas monetarias que los habitantes de dichas tierras debían sufragar en beneficio del Hospital. También aquí la renta era recaudada en el día de San Miguel todos los años y la tasa impositiva variaba según la disponibilidad de animales de labranza de cada poblador, lo que estaba íntimamente ligado a su nivel económico. La Orden percibiría medio de maravedí de todo aquel que tuviera por lo menos un yugo de bueyes o de otros animales. La tasa no aumentaba para los que poseyeran varios yugos. Quien careciera de dicho instrumento de trabajo sólo se vería forzado a entregar un cuarto de maravedí. Finalmente, todo propietario de un caballo que valiera 20 maravedís quedaba exento del tributo. Este sistema (con ligeras variantes locales) fue aplicado en Villacañas, Arenas de San Juan, Madridejos, Camuñas, Herencia, Tembleque, Quero, Alcázar de San Juan, Turleque, Villacañas de Algodor y Villaverde ${ }^{87}$.

Un régimen muy parecido se implantó más al sur, en Lora del Río, durante la segunda mitad del siglo XIII. Según la carta de población de I259 también aquí el habitante que careciera de bueyes u otros animales de labranza pagaba sólo un cuarto de maravedí anual. En cambio sí se aprecia una subida en la carga que correspondía a quien dispusiera de bestias para las labores agrícolas, que pasaba de medio a un maravedí ${ }^{88}$.

Finalmente, las ordenanzas de la villa de Peñalver del año I334 nos pueden servir para conocer el estado de la cuestión en el tema que nos ocupa al final del

84. Ayala Martínez, C., Libro de privilegios..., págs. 237-239, nº 77. Catalina García, Juan, «Carta-puebla de Alhóndiga», Boletín de la Real Academia de la Historia, 35 (1899), pp. 473-474.

85. Ayala Martínez, C., Libro de privilegios..., págs. 391-393, n² 208.

86. Ayala Martínez, C., Libro de privilegios..., págs. $439-441, n^{\circ} 248$.

87. AguiRre, Domingo, El gran priorato de San Juan de Jerusalén en Consuegra, en 1769, Toledo, Instituto Provincia de Investigaciones y Estudios Toledanos, 1973, págs. 96-97, 100, 103, 112, 115, 121, 124, 128, 138. BARQUERO GoÑI, C., Aportación al estudio de la repoblación sanjuanista..., p. 174.

88. González Carballo, José, «Carta-puebla de Lora del Río», Lora del Río. Revista de Estudios Locales, l (1990), p. $34, \mathrm{n}^{\circ} 1$ 
periodo de nuestro estudio. Además, no debemos olvidar que es un lugar del que ya contábamos con datos durante la segunda mitad del siglo XII. A este respecto, lo primero que sorprende es el mantenimiento del mismo tributo anual en métalico pagado por cada casa en el día de San Miguel justo en la misma cifra que ya encontrábamos en el fuero de la decimosegunda centuria: un mencal. Con todo, es muy probable que hubiera variado el tipo de cambio de esta moneda. Según las ordenanzas, por aquella época equivalía a 20 dineros, mientras que un mencal valía sólo cuatro dineros en 1272 también en Peñalver ${ }^{89}$. Sin embargo, además surge ahora otra tributación suplementaria en metálico. Al parecer, la Orden cobraba cuatro mil maravedís del conjunto del Concejo todos los años, y fueron rebajados a dos mil precisamente a partir de $\mathrm{I334}$. Las ordenanzas llaman a estos maravedís «de las mandas» o «pecho forero» ${ }^{90}$.

No es fácil apreciar tendencias generales a partir de datos tan inconexos. Además muchas veces obedecerían a circunstancias puramente locales. Eso sí, parece obvio que los hospitalarios solían preferir el día de San Miguel (29 de septiembre) como fecha para recoger el tributo. La razón de ello muy bien pudiera estribar en que el final del verano fuera el momento en que la recolección del grano ya hubiera finalizado y los campesinos dispusieran de más dinero tras la comercialización de sus productos. Por otra parte, es posible apreciar una lenta subida de las tarifas impositivas a lo largo de todo el periodo de nuestro estudio. También se constata la introducción de una rudimentaria escala de variación de la tasa en función del nivel de riqueza de los habitantes de cada población, pero diferenciando tan sólo dos o a lo sumo tres situaciones. Finalmente, es difícil apreciar el impacto real que estas deducciones tenían sobre la economía campesina de los dominios sanjuanistas. Contamos con los datos ya reseñados del fuero de Trevejo del año I228, de los cuales se deduce que esta renta anual suponía entre un $2 \%$ y un 2,5\% de la riqueza total de un habitante del lugar. No parece que fuera entonces excesivamente elevada. De todas maneras, desconocemos hasta qué punto estos datos pueden ser extrapolables.

La renta por la tierra no siempre se cobraba en metálico. En algunas ocasiones se recaudaba en especie, si bien esto ocurre en un número de casos bastante menor. En concreto, contamos con sólo tres ejemplos bastante cercanos entre sí, que se localizan todos en la zona entre Madrid y Toledo: Villamiel de Toledo, Cedillo del Condado y Humanes de Madrid.

Los habitantes de Villamiel de Toledo tuvieron que dar dos cahíces anuales de cereal hasta el año iı87. A partir de esta fecha el comendador de Consuegra rebajó la contribución a I 8 fanegas, 9 de trigo y 9 de cebada, posiblemente para

89. Ayala Martínez, C., Libro de privilegios..., págs. 566-567, nº 346.

90. Calderón Ortega, José Manuel, «Ordenanzas municipales de la villa de Peñalver», Anuario de Estudios Medievales, 18 (1988), pp. 326-327. 
incentivar el asentamiento de nuevos pobladores ${ }^{91}$. La disminución del gravamen fue sustancial: teniendo en cuenta que un cahíz solía equivaler a doce fanegas en Castilla, ahora eran seis fanegas menos, lo cual constituía un $25 \%$ de la antigua carga.

En Cedillo del Condado a partir del acuerdo de I2I6 existieron diferentes tarifas en especie de acuerdo con la mayor o menor disponibilidad de animales de labranza ${ }^{92}$. Quien labraba la tierra con un yugo de bueyes pagaba un cahíz de cereal (la mitad en trigo y la otra mitad en cebada) al Hospital. El tributo permanecía invariable para los que poseyeran varios yugos. En cambio, quien disponía de un buey para trabajar daba seis fanegas (es decir, la mitad). La presencia de viñas en Cedillo introducía otras variantes. A sus propietarios se les obligaba a pagar el tributo en cereal y la tasa aumentaba en función de la extensión de las viñas. El esquema era el siguiente:

$\begin{array}{ll}\text { Más de tres aranzadas de viñas } & - \text { I cahíz de cereal } \\ \text { Tres aranzadas } & - \text { seis fanegas. } \\ \text { Dos aranzadas } & - \text { cuatro fanegas. } \\ \text { Una aranzada } & - \text { dos fanegas. } \\ \text { Menos de una aranzada } & - \text { Un peón para recoger hierbas y algarrobas. }\end{array}$

La situación de Humanes de Madrid era bastante parecida a la de Cedillo. Hasta I254 la Orden exigía a los pobladores cantidades de cereal variables según el tipo de animales de labranza de cada uno de ellos' ${ }^{93}$ :

$\begin{array}{ll}\text { Sin animales } & - \text { cuatro fanegas. } \\ \text { Con animales excepto bueyes } & - \text { seis fanegas. } \\ \text { Con bueyes, por cada yugo } & - \text { un cahíz. }\end{array}$

Sin embargo, a partir de I255 este sistema de tributación fue sustituído por otro más complejo en el que se tenía en cuenta la extensión de tierra cultivada por cada campesino ${ }^{94}$. Para poder valorar adecuadamente la magnitud de las cargas que acabamos de reseñar contamos con el dato proporcionado por un documento de I255: un yugo de bueyes podía sembrar cada año entre 4,5 y 5 cahíces en las tierras de Humanes y sus alrededores ${ }^{95}$. Como la Orden parece tender a cobrar un cahíz por cada yugo, esto significaba alrededor de una quinta parte de la sembradura.

Existen localidades con una fórmula de contribución mixta, en especie y en metálico. Un buen ejemplo de ello es el del otro Villamiel, al noroeste de la actual

91. Ayala Martínez, C., Libro de privilegios..., pág. 340, nº 158.

92. Ayala Martínez, C., Libro de privilegios..., págs. 402-403, nº 218.

93. Ayala Martínez, C., Libro de privilegios..., págs. $533, n^{\circ} 321$.

94. Ayala Martínez, C., Libro de privilegios..., págs.. 543-544, nº 330.

95. Ayala Martínez, C., Libro de privilegios..., págs.. 542-543, nº 329. 
provincia de Cáceres. Su carta de población de i235 estableció que sus pobladores pagaran anualmente a la Orden un tercio de maravedí, un cuarto de celemín en cebada y seis celemines en trigo ${ }^{96}$. Muy curioso es el caso de Peñalver. A pesar de que ya hemos constatado que en este lugar se pagaba la renta por la tierra sólo en metálico tanto durante el siglo XII como en el XIV, existe un testimonio que prueba la presencia de un sistema mixto a finales de la decimotercera centuria: El fuero de 1272 preveía que todo hombre que morase en Peñalver diera un mencal (al igual que en ir6o y I334), pero además disponía que por cada yugo de bueyes se pagasen cuatro almudes de cereal, la mitad en trigo y la otra mitad en ceba$\mathrm{da}^{97}$. Es una buena muestra de que la realidad debía de ser entonces bastante más dinámica y cambiante de lo que la documentación nos permite vislumbrar. Los sistemas de tributación evolucionarían en función de circunstancias que se nos escapan con frecuencia.

En definitiva, las rentas por la tierra exigidas por la Orden no dan la impresión de ser excesivamente pesadas. Sin embargo, el hecho de que prácticamente nunca falten en los diferentes lugares de la Orden nos lleva a pensar que seguramente se trataría de la segunda gran fuente de ingresos obtenida por los hospitalarios de sus señoríos, inmediatamente detrás del diezmo.

Otra carga señorial presente en algunos de los dominios sanjuanistas era la «fumazga», una cantidad devengada por cada fuego u hogar. En Paradinas de San Juan el propio Concejo ambicionaba apoderarse de este tributo y para evitarlo en II95 el prior del Hospital tuvo que ceder a dicho Concejo la tercera parte de la renta que la Orden cobraba a los hombres de Paradinas por las tierras que trabajaban ${ }^{98}$. El ejemplo que acabamos de citar es una buena muestra del valor que podía llegar a alcanzar la contribución desde la perspectiva hospitalaria. Sin embargo, no son muchos los lugares donde constatamos su presencia. Además de Paradinas, tan sólo encontramos otro testimonio en la cercana localidad de Fresno el Viejo. El acuerdo de i286 entre el prior del Hospital y el Concejo de Fresno nos informa de que la Orden de San Juan cobraba por este concepto un octavo de onza en trigo de cada casa. El recaudador de la Orden recogería el tributo desde el día de San Miguel (29 de septiembre) hasta Navidad (25 de diciembre) todos los años. Tan sólo cuatro alberguerías, los alcaldes y el propio recaudador locales quedarían exentos de su pago ${ }^{99}$.

El pago del «yantar» a miembros de la Orden no parece hallarse muy extendido entre las poblaciones sanjuanistas. Durante los siglos XII y XIII tan sólo lo encontramos constatado en tres lugares muy diferentes: Peñalver, Trevejo y Fresno el Viejo. En el primero de ellos se había ya convertido en una cantidad fija de dinero

96. Ayala Martínez, C., Libro de privilegios..., págs. $462-463, n^{\circ} 264$
97. Ayala Martínez, C., Libro de privilegios..., págs. $566-567, n^{\circ} 346$.
98. Ayala Martínez, C., Libro de privilegios..., págs. $366-367, n^{\circ} 183$.
99. Ayala Martínez, C., Libro de privilegios..., págs. $608-611, n^{\circ} 380$. 
hacia la segunda mitad del siglo XII. Concretamente, consistía en el pago anual de cuatro maravedís al comendador por parte de los vecinos de Peñalver ${ }^{100}$. En cambio todavía no había perdido su primitivo carácter de prestación de víveres en Trevejo durante el siglo XIII. El destinatario en este caso era el Prior de la Orden o su sustituto. El fuero de 1228 prescribía que cada pastor debía darle todos los años una gallina y dos panes. Además, el conjunto de la población le entregaría dos cerdos que valieran cuatro maravedís, seis cabritos y diez vasijas de vino ${ }^{\text {Ior }}$. En Fresno el Viejo la situación era muy parecida. A partir de I286 se acordó que el Concejo pagara al Prior una vez al año como yantar cuatro carneros, treinta gallinas y cuatro cabritos si el tributo fuera recogido durante los meses de abril o de mayo. Si la recaudación se realizara en otra época del año su composición cambiaría y pasarían a ser cuatro ocas en lugar de los cabritos, sesenta panes, vino por valor de un maravedí y doce heminas de cebada ${ }^{\mathrm{ro2}}$. Da la impresión de que el yantar conservaba su originario sentido de manutención de su señor el Prior en los dos últimos casos analizados.

Nuestras fuentes recogen algunos otros derechos del Hospital que sólo los señores cobraban. Así ocurría con la mañería, que únicamente aparece en el fuero de Atapuerca, un texto antiguo y arcaico. Si uno de los habitantes de la villa careciera de hijos en el momento de fallecer, su familiar más próximo tendría que pagar cinco sueldos para heredar sus bienes ${ }^{103}$. Muy próximo debemos considerar al tributo que había de abonar a partir de i255 el hijo y heredero de todo propietario en Humanes de Madrid después de la muerte de éste ${ }^{\mathrm{I04}}$.

Otra prestación era la de las acémilas, consistente en proporcionar animales de transporte o dinero para alquilarlos. En principio parece tratarse de un derecho de la monarquía ${ }^{105}$. En efecto, tendremos ocasión de conocer más adelante varias concesiones reales de este derecho en favor de los hospitalarios. Sin embargo, también lo incluímos aquí porque existe un caso en el que no parece haber mediado una cesión de este tipo. El fuero de Trevejo de I228 obligaba al Concejo a proporcionar doce animales una vez al año, cuando el Hospital hiciera una expedición armada contra los musulmanes. Seis de las bestias llevarían odres y las otras seis irían con sacos. La prestación podía conmutarse a cambio de enviar a sus expensas seis ballesteros con los hospitalarios ${ }^{\mathrm{I0} 6}$. Tanto la vigencia posterior de esta prestación como la posibilidad de su sustitución por una suma de dinero están documentadas varios decenios más tarde. En I30o el rey Fernando IV

100. Ayala Martínez, C., Libro de privilegios..., págs. 237-239, nº 77.

101. Ayala Martínez, C., Libro de privilegios..., págs. 439-441, nº 248.

102. Ayala Martínez, C., Libro de privilegios..., págs. 608-611, nº 380

103. Martínez Díez, Gonzalo, Fueros locales en el territorio de la provincia de Burgos, Burgos, Institución Fernán González, 1982, pág. 148.

104. Ayala Martínez, C., Libro de privilegios..., págs. 543-544, nº 330.

105. LADERO QUESADA, Miguel Ángel, Fiscalidad y poder real en Castilla (1252-1369), Madrid, Universidad Complutense, 1993, págs. 46-47.

106. Ayala Martínez, C., Libro de privilegios..., págs. 439-441, n² 248 
prohibió que se exigiera al Concejo un número de acémilas mayor de doce o una suma superior a sesenta maravedís por cada animal ${ }^{107}$.

En Fresno el Viejo la Orden también poseía este derecho. El acuerdo de I286 establecía que los de Fresno dieran las mismas acémilas a la Orden que las que proporcionaran otros abadengos de la diócesis de Salamanca cuando el rey las reclamase por aquella tierra ${ }^{\mathrm{I0} 8}$. Sin embargo, en este caso sí conocemos con certeza que el monarca había cedido previamente esta prestación a los hospitalarios en $\mathrm{I} 28 \mathrm{I}^{\mathrm{IO9}}$.

Las prestaciones de trabajo personal o «sernas» ${ }^{\mathrm{IIO}}$ aparentemente no eran frecuentes en los dominios de la Orden en la Corona de Castilla. Tan sólo hemos encontrado dos referencias sobre ellas en la documentación de nuestro periodo de estudio. En ninguno de los dos casos era la única fórmula de pago de los vasallos de la Orden, sino que convivía con otros sistemas. La evidencia más antigua nos la proporciona el fuero de Atapuerca de Iı38. En él se establecía que los habitantes de la villa debían prestar cuatro días de trabajo anuales al Hospital. Dos de ellos serían para arar y uno para talar. En esos tres días quienes tuvieran bueyes habrían de acudir con ellos. La tarea a realizar en el cuarto día sería la siega. La Orden habría de proporcionar alimento a los operarios durante dos de las jornadas de trabajo. Cada ración de comida consistiría en una cantidad suficiente de pan, vino y carne, junto con hortalizas o legumbres bien condimentadas con queso o mantequilla. En caso de faltar este alimento los habitantes no estarían obligados a trabajar ${ }^{\mathrm{II}}$.

También constatamos de la presencia de sernas en el texto del acuerdo entre el prior sanjuanista y el concejo de Fresno el Viejo de i286. Entonces quedó fijado que los pobladores de Fresno que tuvieran bueyes proporcionaran yugos de dichos animales con todo su equipo de trabajo un día al año para arar. La jornada en cuestión sería libremente elegida por el representante de la Orden, con las dos únicas limitaciones de que se desarrollara dentro del término de Fresno el Viejo y de que se avisara de ello con una antelación mínima de dos días a los afectados. El Hospital tendría que proporcionar a los que acudieran a trabajar pan, vino y queso en abundancia sobre el mismo campo de labranza, y posteriormente a su vuelta habría de darles buena cantidad de pan, vino y carne en la casa de la Orden ${ }^{\mathrm{II}}$.

Según los datos reseñados el valor de estas prestaciones para los freires sanjuanistas no sería excesivamente significativo, ya que se trata siempre de unas

107. Biblioteca de la Real Academia de la Historia, Manuscrito 9/1084, Colección de don Luis de Salazar y Castro, volumen $\mathrm{O}-3$, folios $165 \mathrm{~V}-167 \mathrm{r}$.

108. Ayala Martínez, C., Libro de privilegios..., págs. 608-611, n³ 380 .

109. Ayala Martínez, C., Libro de privilegios..., págs. 576-577, n 355 .

110. Véase Alfonso Saldaña, María Isabel, «Las sernas en León y Castilla. Contribución al estudio de las relaciones socio-económicas en el marco del señorío medieval», Moneda y Crédito, 129 (1974), pp. 153-210.

111. Martínez Díez, Gonzalo, Fueros locales en el territorio de la provincia de Burgos, Burgos, Institución Fernán González, 1982, pág. 148.

112. Ayala Martínez, C., Libro de privilegios..., págs. 608-611, n³ 380. 
pocas jornadas de trabajo al año y tan sólo las encontramos en dos localidades. Además, no era un servicio gratuito y totalmente ventajoso para la Orden, pues los hospitalarios tenían que hacerse cargo de la alimentación de los hombres a quienes afectase la obligación mientras durase ésta.

A pesar de todo lo que acabamos de exponer arriba, sospechamos que el panorama que nos ofrece nuestra documentación en el tema que nos ocupa está deformado por el azar en la conservación de fuentes. En efecto, el Becerro de las Behetrías nos permite conocer que a mediados del siglo XIV había quince entidades de población ${ }^{\mathrm{II}}$ bajo el señorío exclusivo de la Orden de San Juan y otras once ${ }^{\mathrm{II} 4}$ cuyo dominio compartía la Orden con otras personas e instituciones dentro de la zona cubierta por el Becerro (el extremo nordeste de la Corona de Castilla, grosso modo) donde pervivían las sernas. Estas, además, con frecuencia son bastante más de unos pocos días al año y se acercan a una periodicidad mensual. Por tanto, parece probable que el cuadro mostrado por la documentación conservada de los siglos XII y XIII no se adecúe a la realidad y que las prestaciones de jornadas de trabajo tuvieran un lugar más destacado en el cuadro de los derechos señoriales hospitalarios, en especial al norte del Duero, de lo que parece. Con todo, tampoco conviene exagerar su importancia pues siempre aparecen acompañadas del pago de otras rentas en especie o en metálico dentro del mismo Becerro de las Behetrías.

\section{TASAS SOBRE EL PASO DE MERCANCIAS.}

La Orden de San Juan se benefició del cobro de algunas contribuciones indirectas. Concretamente son dos tipos los que encontramos documentados: portazgos y montazgos.

Los hospitalarios disfrutaron de la percepción en algunos lugares de una tasa sobre la circulación de productos como era el portazgo ${ }^{\mathrm{II}}$. González Mínguez ha llamado la atención sobre el valor polisémico de este concepto, si bien adelanta un esbozo de definición como «impuesto indirecto que afectaría al tránsito de bienes muebles, aunque también podría cobrarse por las personas, y ocasionalmente, a las transacciones comerciales y a ciertas operaciones anejas, como la exposición y pesaje

113. Martínez Díez, Gonzalo, Libro Becerro de las Behetrías. Estudio y texto crítico, León, Centro de Estudios e Investigación San Isidoro, 1981, volumen I, págs. 162, 165, 180, 183, 184, 187-188, 188, 188-189, 215, 218, 221-222, 239, 327; volumen II, págs. 273, 399-400.

114. Martínez Díez, G., Libro Becerro..., volumen I, págs. 179-180, 182, 196, 204, 219-220, 231-232, 309-310, 312-313, 313, 344-345; volumen II, pp. 274-275.

115. Sobre los portazgos castellano-leoneses, véanse González Mínguez, Cesar, El Portazgo en la Edad Media. Aproximación a su estudio en la Corona de Castilla, Bilbao, Universidad del País Vasco, 1989, y Porras Arboledas, Pedro Andrés, «Los portazgos en León y Castilla durante la Edad Media. Política real y circuitos comerciales», En la España Medieval, 15 (1992), pp. 161-211. 
de mercancías, y sería cobrado bien a las puertas de las ciudades o en otros lugares de paso o en el propio lugar del mercado» ${ }^{\mathrm{II}}$.

En nuestro caso, el primero del que tenemos noticias es el de Consuegra. Durante el siglo XII dicha localidad era uno de los puntos, junto con Toledo, Calatrava y Paracuellos, en los que se cobraban derechos a las recuas que comerciaban con tierras islámicas ${ }^{117}$. Sabemos que ya existía antes de que el lugar pasara a depender de los freires sanjuanistas. En II73 el rey Alfonso VIII dispuso que las recuas provistas de mercancías que pasaran por Consuegra y fueran a territorio musulmán por la ruta de Segura pagaran portazgo en Consuegra. En cambio, si viajaran por Consuegra pero sin pasar por Segura, abonarían dicho tributo a los freires de Calatrava ${ }^{\mathrm{II} 8}$. Cuando el mismo monarca entregó el castillo consaburense al Hospital diez años después incluyó al mencionado portazgo en la concesión ${ }^{\mathrm{II}}$.

A finales del siglo XII la importancia de Consuegra en la ruta comercial con la España musulmana debió de crecer como consecuencia de la ocupación de Calatrava y su Campo por los almohades entre los años II95 y I2I2 ${ }^{\text {I20 }}$. El hecho es que en el año I20o el rey castellano Alfonso VIll otorgó salvaguardia tanto en la ida como en la vuelta a todos aquellos que llevaran recuas desde Toledo a tierras de los musulmanes y quisieran ir por Consuegra, a condición de que dieran los derechos correspondientes en esta última localidad y pagaran el portazgo a los freires «de Consuegra», es decir, a los hospitalarios ${ }^{121}$. Es verosímil que Consuegra hubiera sustituido entonces a Calatrava en el papel de última etapa castellana para los mercaderes antes de penetrar en territorio almohade y que los freires sanjuanistas obtuvieran suculentos beneficios de ello a través del portazgo. No olvidemos que por entonces (II97-I2II) había un periodo de tregua en la frontera ${ }^{122}$.

Varios decenios después seguía cobrándose. En I250 el gran comendador de España ordenaba al comendador de Consuegra que los hospitalarios reclamaran portazgo a cada persona una sola vez dentro del término consaburense $\mathrm{e}^{\mathrm{I} 23}$.

El de Consuegra fue el principal portazgo obtenido por la Orden. Conocemos que también consiguió algunos otros, pero su importancia debió de ser menor. Por ejemplo, cuando el rey Alfonso X dio Quiroga y Cubillas de Duero a los freires

116. González Mínguez, C., El Portazgo..., pág. 97.

117. Porras Arboledas, P. A., Los portazgos..., p. 196.

118. GonzÁlez, Julio, El reino de Castilla en la época de Alfonso VIII, Madrid, CSIC, 1960, volumen II, págs. 297-298, $\mathrm{n}^{\circ} 176$.

119. «et cum omnibus portaticis suis»: Ayala Martínez, C., Libro de privilegios..., págs. 322-324, n 144. Guerrero Ventas, que reproduce la edición de este documento realizada por Clemente de Aróstegui en el siglo XVIII, transcribe «portatiis». Guerrero VentAS, Pedro, El gran priorato de la Orden de San Juan de Jerusalén en el Campo de la Mancha, Toledo, Diputación Provincial, 1969, págs. 332-333, n 4.

120. González, J., El reino de Castilla..., I, págs. 969, 1016-1017. GonzÁLEz, Julio, Repoblación de Castilla la Nueva, Madrid, Universidad Complutense, 1975, volumen I, págs. 235 y 240.

121. Archivo General de Palacio, Infante don Gabriel, Secretaría, legajo 564, Visitas y Autos, folio $20 v$.

122. GonzÁlez, J., El reino de Castilla..., volumen I, págs. 979-981. GonzÁlez, J., Repoblación de Castilla..., volumen I, pág. 238.

123. Archivo General de Palacio, Infante don Gabriel, Secretaría, legajo 564, Visitas y Autos, folios 7r-8r. 
sanjuanistas en I28I incluyó a los portazgos que se cobraban en esos dos lugares dentro de la concesión ${ }^{\mathrm{I24}}$. Con todo, el de Quiroga pudo tener cierta relevancia, pues se le cita de manera particularizada en el texto de las amplias permutas de I27I y I28I I25. No volvemos a tener más noticias de ninguno de los dos, por lo que suponemos que no serían muy lucrativos.

Otro derecho que sólo hasta cierto punto podríamos considerar de tránsito fue el de montazgo sobre el ganado que el Hospital percibió preferentemente en su señorío de la Mancha ${ }^{\mathrm{I} 26}$. La relevancia de los pastos de la llanura manchega debió de atraer bastantes rebaños trashumantes y propició un rápido desarrollo del montazgo. Ya se menciona explícitamente su presencia en los pactos que los hospitalarios acordaron con los poderes vecinos, el arzobispado de Toledo y las órdenes de Calatrava y Santiago, en el segundo cuarto del siglo XIIl. La primera cita se encuentra en el acuerdo de 1228 con el arzobispo don Rodrigo. En dicho texto se preveía que los freires sanjuanistas podrían cobrar montazgo en Lillo, El Romeral y Dancos salvo a los pobladores de los tres lugares. Estos habitantes sólo tendrían que pagarlo si entraran en el término de Consuegra ${ }^{\mathrm{I2}}$. El segundo pacto con la iglesia toledana de 1229 repetía las mismas condiciones con respecto a esta $\operatorname{tasa}^{128}$. La avenencia de 1232 con los freires calatravos establecía que «de los montadgos que cada una de las órdenes monte en su término» ${ }^{\mathrm{I2}}$. El acuerdo de $\mathrm{I} 237 \mathrm{con}$ la orden de Santiago sobre los límites de los respectivos dominios en la Mancha también señala la existencia del montazgo al prescribir que quedaban exentos de él los ganados y pastores pertenecientes a las dos órdenes. El resto de los rebaños sí que debían pagar montazgo al entrar en el término de cada una de las órdenes ${ }^{130}$.

Sin embargo, hay que esperar hasta los años centrales del siglo para que la perpepción de dicho montazgo quede perfectamente regulada y configurada. Una carta del gran comendador del Hospital en España al comendador de Consuegra fechada en el día in de noviembre de I250 nos informa de la asistencia de aquel a unas cortes celebradas en Sevilla en las que el rey estableció unas tasas para la recaudación de montazgos en sus reinos y ordenó que las órdenes militares y los concejos no los cobraran en más de un lugar. El gran comendador comunicó las

124. Rodríguez Campomanes, Pedro, Disertaciones históricas del Orden y Caballería de los Templarios, Barcelona, El Albir, 1975, págs. 231-232. Ayala Martínez, C., Libro de privilegios..., págs. 575-576, nº 354.

125. González JıméneZ, Manuel (Ed.), Diplomatario andaluz de Alfonso X, Sevilla, Fundación El Monte, 1991, págs. 403 y 503.

126. Sobre esta tasa, véanse KLEIN, Julius, La Mesta. Estudio de la historia económica española. 1273-1836, Madrid, Alianza, 1979, págs. 155-156, 169-171, y BARQUERO GoÑI, Carlos, «Los hospitalarios castellanos y la Mesta: el acuerdo de 1434», Espacio, Tiempo y Forma. Serie III. Historia Medieval, 13 (2000), pp. 45-56.

127. FITA, Fidel, «La Guardia, villa del partido de Lillo, provincia de Toledo. Datos históricos», Boletín de la Real Academia de la Historia, 11 (1887), pp. 385-388. Las alusiones al montazgo se hallan en la p. 387.

128. FiTA, F., La Guardia..., pp. 388-392. La parte que nos interesa ahora está en la p. 391.

129. Ortega y Cotes, Ignacio José, Álvarez de Baquedano, Juan Francisco y Ortega Zúñiga y Aranda, Pedro de, Bullarium Ordinis Militiae de Calatrava, Barcelona, El Albir, 1981, págs. 64-66. El fragmento citado se encuentra en la pág. 65.

130. Lomax, Derek W., La Orden de Santiago (1170-1275), Madrid, CSIC, 1965, págs. 257-262, n² 24. La cláusula a la que nos referimos se halla en la pág. 260. 
nuevas tarifas al delegado hospitalario en Consuegra y le ordenó que las hiciera respetar. Eran las siguientes: dos vacas por cada mil cabezas de ganado bovino o cuatro maravedís por vaca, dos carneros por cada mil ovejas o un maravedí por cabeza, y finalmente dos cerdos de cada mil o un maravedí por cada ejemplar.

Más interesante para nosotros es el hecho de que el gran comendador mencione que los hospitalarios solían cobrar montazgo y asadura en dos lugares, Consuegra y Peñarroya. En cumplimiento de la disposición regia, ordenó al comendador que en lo sucesivo sólo percibieran montazgo en Consuegra ${ }^{\text {I3I }}$. Quedaba así perfectamente definida la recaudación del montazgo que hemos visto implantarse en el señorío manchego de la Orden de San Juan durante la primera mitad del siglo XIII.

Con todo, es probable que haya que retrasar algo la cronología de la citada carta. En efecto, su contenido se corresponde bastante bien (con algunas variantes en las tarifas) con los cuadernos de las cortes reunidas en Sevilla por Alfonso X en I252I253 $3^{132}$. El monarca promulgó en esa ocasión la norma de que cada orden militar sólo cobrara montazgo sobre el ganado que viniera a «estremo» (la Extremadura tal y como se entendía en la época, las tierras al Sur del Duero) en un lugar de la tierra de Castilla y en otro de la de León. Sabemos ahora que fue Consuegra el emplazamiento escogido en Castilla por el Hospital, pero seguimos desconociendo en qué lugar de León también percibiría montazgo.

Algún oficial sanjuanista también intentó cobrar tasas sobre el ganado trashumante que recorría las tierras puestas a su cargo en otra región de la Corona de Castilla. Concretamente, esto ocurrió por lo menos una vez en Andalucía. El comendador de Lora del Río empezó a tomar la mitad del diezmo de los ganados «estremennos» que entraban en el término de dicha localidad. Alfonso X tuvo que intervenir en 1280 para impedírselo ${ }^{133}$.

Es probable que los hospitalarios tuvieran otra fuente de ingresos en los derechos sobre los mercados que se celebraban en poblaciones pertenecientes a su señorío. Las fuentes citan la existencia de algunos de ellos. Alcázar de San Juan tuvo un mercado semanal todos los jueves a partir de $1292^{134}$. Otra villa de la Orden, Támara, dispuso desde 1333 del privilegio de celebrar un mercado semanal todos los viernes ${ }^{135}$. Parece verosímil pensar que el Hospital obtuviera algún provecho de ellos, aunque la documentación no diga nada al respecto.

131. Archivo General de Palacio, Infante don Gabriel, Secretaría, legajo 564, Visitas y Autos, folios 7 recto-8 recto.

132. Rodríguez Díez, Matías, Historia de la ciudad de Astorga, $2^{a}$ edición, Astorga, Porfirio López, 1909, págs. 709710. Procter, Evelyn S., Curia y Cortes en Castilla y León, 1072-1295, Madrid, Cátedra, 1988, págs. 294-295.

133. González Jıménez, Manuel (Ed.), Diplomatario andaluz de Alfonso X, Sevilla, El Monte, 1991, pág. 487, $n^{\circ} 460$.

134. Rubio Herguido, Manuel, «El escudo de Alcázar», Noria. Cuadernos de temas alcazareños, i (1962), pp. 7 y 9. Archivo General de Palacio, Infante don Gabriel, Anexo, legajo 1, n² 22.

135. Archivo Histórico Nacional, Órdenes Militares, carpeta 576, $n^{\circ} 2$. 


\section{CONTRIBUCIONES DE NATURALEZA ECLESIÁSTICA.}

Los ingresos de naturaleza eclesiástica que la Orden de San Juan obtenía de sus iglesias eran muy variados. Podían abarcar conceptos tales como derechos de sepultura, primicias, ofrendas diversas... Sin embargo, el más significativo sin duda era el diezmo. Es sobre el que mayor información disponemos y, por tanto, sobre él centraremos nuestra atención ${ }^{\mathrm{I} 36}$.

Con independencia de su mayor o menor legalidad, el hecho es que los hospitalarios castellano-leoneses cobraban diezmos y primicias desde fechas muy tempranas. Los textos de las donaciones de Paradinas de San Juan y de Fresno el Viejo a comienzos del siglo XII ya incluían explícitamente a diezmos y primicias entre los derechos transmitidos a la Orden de San Juan ${ }^{137}$. También cuando los vecinos de Medina de Pomar dieron la iglesia de Santa María al Hospital de Jerusalén en II62 lo hicieron «con diezmos, con primicias, con ofrendas y con todas las rentas que pertenecen a la Santa Iglesia» ${ }^{138}$. Finalmente, en una fecha tan tardía como I28I todavía Alfonso X al entregar la iglesia de Santa María de Castrillo de Vega a la Orden, lo hizo con sus diezmos y primicias ${ }^{139}$.

Creemos que estas declaraciones no se quedaban en meras palabras, por que el contenido de varios de los fueros y cartas de población otorgados por los freires sanjuanistas también hacen alusión al pago de dichas rentas de naturaleza eclesiástica a la Orden. El fuero de Alhóndiga en II7o prescribía que cada uno de los vecinos de dicha localidad debía dar diezmos y primicias a la iglesia del Hospital $^{140}$. El fuero de I228 ordenaba a los habitantes de Trevejo que abonaran los mismos dos tributos al templo de la Orden edificado en el lugar ${ }^{\text {r4 }}$. En 1248 dos de las cartas-pueblas sanjuanistas de la Mancha, las de Turleque y Villacañas de Algodor, también tenían una cláusula muy parecida: «estos pobladores han de dar diezmo y primicia a la Orden $»^{142}$.

El contenido de varios acuerdos de los hospitalarios con diferentes monasterios nos reafirma en la misma idea, puesto que frecuentemente incluían cláusulas referentes al cobro de diezmos eclesiásticos. Es lo que ocurría, por sólo dar

136. Un estudio pionero sobre los diezmos en León y Castilla durante el periodo de nuestro estudio y además con bastantes alusiones a los hospitalarios fue el de MARTín, José Luis, «Diezmos eclesiásticos. Notas sobre la economía de la sede zamorana (s. XII-XIII)», Actas de las I Jornadas de Metodología aplicada de las Ciencias Históricas. II Historia Medieval, Santiago de Compostela, 1975, pp. 69-78. Otras obras destacadas sobre el tema son: Guadalupe BerazA, María Luisa, Diezmos de la sede toledana y rentas de la mesa arzobispal (Siglo XV), Salamanca, Universidad de Salamanca, 1972. Ladero Quesada, Miguel Ángel y GonzÁlez Jiménez, Manuel, Diezmo eclesiástico y producción de cereales en el reino de Sevilla (1408-1503), Sevilla, Universidad de Sevilla, 1978.

137. Aguirre, Domingo, El gran priorato..., págs. 41-42. Ayala Martínez, C., Libro de privilegios..., págs. 146-147, $n^{\circ} 5$ y págs. 149-150, $n^{\circ} 7$. Archivo Histórico Nacional, Órdenes Militares, caja $7491^{2}, n^{\circ} 30$

138. Ayala Martínez, C., Libro de privilegios..., págs. 249-250, nº 87.

139. GonZÁlez JıméneZ, Manuel (Ed.), Diplomatario andaluz de Alfonso X, Sevilla, El Monte, 1991, págs. 501-502, nº 478

140. Catalina Garcia, Juan, «Carta-puebla de Alhóndiga», Boletín de la Real Academia de la Historia, 35 (1899), p. 473.

141. Ayala Martínez, C., Libro de privilegios..., págs. 439-441, nº 248.

142. AguirRe, D., El gran priorato..., pág. 113. BARQUERo GoÑI, C., Aportación al estudio de la repoblación sanjuanista..., p. 174 . 
algunos ejemplos, en los siguientes pactos: con el monasterio de San Román de Hornija en $\mathrm{I} 203^{\mathrm{I} 43}$, con los cenobios de San Isidoro de León y Trianos en II99 $9^{\mathrm{I} 44} \mathrm{y}$ con el de Sahagún en I2I2 ${ }^{145}$. También hacía referencia a ello la sentencia judicial de I2I3 sobre un pleito entre la Orden de San Juan y el monasterio de Osera ${ }^{\mathrm{I} 46}$.

Quizá el testimonio más evidente sea que el cobro de ciertos diezmos por el Hospital fue motivo de queja del arzobispo de Toledo en dos ocasiones por lo menos, durante los años II75 y I2 $13^{\mathrm{I} 47}$.

Los freires sanjuanistas percibían diezmos eclesiásticos cuando controlaban iglesias que tuvieran el rango de parroquia. Esta situación se producía con frecuencia en el interior de sus señoríos, pero no siempre era así. Además, también podía ocurrir que un templo parroquial dependiente del Hospital se hallase dentro de una población que no fuera señorío de la Orden. Finalmente, casi nunca los hospitalarios llegaron a disfrutar de diezmos completos porque normalmente debían entregar una parte al obispo de la diócesis correspondiente. Todas estas observaciones son fácilmente comprobables al leer las diferentes avenencias que la Orden de San Juan hizo con el episcopado castellano-leonés a fines del siglo XII y durante la primera mitad del XIII. Lo más común era un reparto del producto de los diezmos, correspondiendo un tercio al obispo y dos a la Orden, pero la situación podía variar bastante según la diócesis y también a nivel local.

En el caso de Fresno el Viejo es posible que el Hospital llegara a controlar la totalidad de los diezmos de la aldea, porque el obispo de Salamanca hizo renuncia de su tercia episcopal en favor de los freires sanjuanistas en II2 $\mathrm{I}^{148}$. Sin embargo, se trata de un ejemplo excepcional. Más de un siglo después, en I232, un acuerdo entre el obispo de Salamanca y la Orden consagró el principio de que el prelado tendría la tercia pontifical de los diezmos en las iglesias hospitalarias de la diócesis. Tan sólo quedaba en reserva el caso del templo de San Juan de Barbalos, sobre el cual estaba pendiente una sentencia que decidiera si debía dar la tercera o la cuarta parte $\mathrm{I}^{\mathrm{I4}}$.

Una situación muy diferente a la de Fresno el Viejo fue la que imperó a partir de iı8I en la iglesia hospitalaria de Santa María de la Vega, en Olmedo, en la cual el obispo de Avila estableció una división del diezmo muy distinta, reservándose

143. Ayala Martínez, C.,, Libro de privilegios..., págs. 376-378, nº 194.

144. Archivo Histórico Nacional, Sellos, caja 97, $n^{\circ} 21$.

145. Fernández Flórez, José Antonio, Colección diplomática del monasterio de Sahagún (857-1300). V (1200-1300), León, Centro de Estudios e Investigación San Isidoro, 1994, págs. 75-76, nº 1584.

146. Romaní Martínez, Miguel, A Colección Diplomática do Mosteiro Cisterciense de Santa María de Oseira (Ourense) (1025-1310), Santiago, Tórculo, 1989, volumen I, págs. 156-158, nº 152.

147. Delaville Le Roulx, Joseph, Cartulaire général de l'Ordre des Hospitaliers de Saint Jean de Jerusalem, 1100-1310, París, Ernest Léroux Éditeur, 1894-1906, volumen I, págs. 334-335, nº 485. Archivo Histórico Nacional, Sellos, caja 5, $n^{\circ} 15$.

148. Ayala Martínez, C., Libro de privilegios..., págs. 157-158, nº 14.

149. Martín Martín, José Luis y otros, Documentos de los Archivos Catedralicio y Diocesano de Salamanca (siglos XII y XIII), Salamanca, Universidad de Salamanca, 1977, págs. 269-270, nº 186. 
él un tercio, correspondiendo otro tercio a los propios feligreses para las necesidades de la fábrica del templo y quedándo tan sólo el tercio restante a la Orden ${ }^{150}$.

En la diócesis de León a partir de iı82 la Catedral recibiría la tercera parte de las rentas decimales correspondientes a las iglesias de la Orden, con la excepción de aquellos templos en los que la costumbre hubiera introducido un régimen diferente ${ }^{\mathrm{ISI}}$. El mantenimiento de la deducción de una tercia años más tarde es demostrado por el acuerdo suscrito entre el obispo leonés y el prior sanjuanista en I24I con motivo de la incorporación de dos nuevas iglesias al Hospital ${ }^{152}$. Además, en el caso de esta diócesis tenemos la fortuna de contar con una fuente excepcional para la cuestión como es el Becerro de Presentaciones ${ }^{153}$. Los datos que nos proporciona permiten comprobar que efectivamente la práctica habitual durante el siglo XIII era que la orden militar cobrara dos tercios del diezmo y tuviera que hacer entrega del resto. Sin embargo, el Becerro también ofrece varios ejemplos de soluciones diferentes, si bien son minoritarios ${ }^{154}$.

En Castronuño y el valle del Guareña el sistema era muy parecido, pero con algunas particularidades importantes. El acuerdo de iı86 con el obispo de Zamora establecía que correspondería al episcopado la tercera parte de los diezmos de corderos y de todo tipo de cultivos excepto leguminosas percibidos en la iglesia de Castronuño. El resto iría a parar al Hospital. En los templos del valle del Guareña un tercio de las rentas decimales de trigo, cebada, centeno y vino pasarían a parar al prelado. Los diezmos de otros productos serían para el Hospital en su totalidad ${ }^{155}$. De todas formas, las diferencias son menores de lo que parece, puesto que los cultivos en cuyos diezmos el obispo tenía participación debían de ser los predominantes en la región.

$\mathrm{Al}$ igual que en el caso leonés, evidencias posteriores muestran la preservación de la tercia episcopal durante el siglo XIIl. En I208 la Orden de San Juan se comprometió a pagar a la iglesia de Zamora la tercera parte de los diezmos que recaudase su templo de Santa María de la Vega en Toro si éste llegara a convertirse en parroquia algún día ${ }^{156}$. A comienzos del siglo XIV la práctica se convirtió en regla general. La avenencia de 1302 entre el obispo y el prior del Hospital estableció que

150. Barrios García, Ángel, Documentación medieval de la Catedral de Avila, Salamanca, Universidad de Salamanca, 1981 , págs. $15-17, \mathrm{n}^{\circ} 18$.

151. Fernández Catón, José María, Colección documental del Archivo de la Catedral de León (775-1230). V (1109-1187), León, Centro de Estudios e Investigación San Isidoro, 1990, págs. 521-524, nº 1.629.

152. Ruiz Asencio, José Manuel, Colección documental del Archivo de la Catedral de León VIII (1230-1269), León, Centro de Estudios e Investigación San Isidoro, 1993, págs. 80-81, nº 2034.

153. Fernández FlóreZ, José Antonio, «El «Becerro de presentaciones» códice 13 del Archivo de la Catedral de León. Un parroquial leonés de los siglos XIII-XV», León y su Historia. Miscelánea Histórica, León, Centro de Estudios e Investigación San Isidoro, 1984, volumen V, págs. 263-565.

154. Rodríguez-Picavea Matilla, Enrique, «Las órdenes militares en la diócesis de León: el Becerro de presentaciones», Congreso de Jóvenes Historiadores y Geógrafos. Actas, Madrid, 1990, volumen I, pp. 703-704.

155. Archivo Catedralicio de Zamora, Tumbo Negro, ff. 3ov-3ir.

156. Martín, José Luis, Documentos Zamoranos. I. Documentos del Archivo Catedralicio de Zamora. Primera Parte (1128-1261), Salamanca, Universidad de Salamanca, 1982, pág. 58, nº 67. 
el obispo o el cabildo catedralicio tuvieran siempre un tercio de los diezmos en todos los lugares sanjuanistas de la diócesis, mientras que los freires de la Orden conservarían los dos tercios restantes ${ }^{157}$.

Un caso especial dentro de este obispado lo constituía la iglesia de Santa María de Peleas de Arriba debido al hecho de que el Hospital era sólo uno de los patronos del templo. Por eso su cuota de renta decimal era aquí menor, quedando fijada en algo menos de dos novenos a partir de $1239^{158}$.

En la diócesis de Ciudad Rodrigo el acuerdo de iı95 también sancionó la reserva de un tercio de los diezmos (con la curiosa excepción de los correspondientes a gallinas y gansos) para el obispo en la iglesia de Trevejo y en la parroquia que la Orden mantenía en la misma cabeza de la demarcación eclesiástica. Con todo, también aquí se daba una situación excepcional. Fuera de la regla general se encontraban los hombres y la iglesia de Fraxinete, por lo cuales el prior y los freires sanjuanistas se limitarían a pagar dos maravedís anuales al obispo. El texto no lo deja claro, pero quizá con ello la Orden obtuviera la totalidad de los diezmos correspondientes a dicho templo ${ }^{159}$.

En la diócesis de Sigüenza sólo había una parroquia hospitalaria dotada del derecho a percibir diezmos en Almazán. El acuerdo de I20o fijó la siguiente división de su producto: un tercio para el episcopado, otro tercio para los clérigos de Almazán y tan sólo una tercera parte para la Orden de San Juan ${ }^{160}$.

El pacto de 1228 con el arzobispo de Toledo pone de manifiesto la existencia de situaciones muy diversas en el interior del extenso territorio cubierto por la archidiócesis. Por un lado, numerosos templos de la Orden quedaron marginados del cobro de diezmos. Además había una parroquia, la de Alexar ${ }^{161}$, de la cual el arzobispo se llevaba nada menos que la mitad del diezmo. En cambio, sólo obtuvo un tercio de las rentas decimales procedentes de la iglesia de Villamiel de Toledo y de las del término de Consuegra, con excepción del templo consaburense de San Pedro, que era de la exclusiva jurisdicción arzobispal ${ }^{162}$. El siguiente acuerdo de I229 mantuvo esta situación con pequeñas modificaciones. Por un lado aclaró que el pago anual de dos maravedís de la iglesia de Alixar que se hacía al arzobispo era en concepto de diezmos del vino, y por otra parte hizo extensivas las condiciones establecidas para las iglesias del término de Consuegra a las del término de

157. Archivo de la Catedral de Zamora, legajo 36, $n^{\circ} 9$.

158. Archivo de la Catedral de Zamora, legajo 21, $\mathrm{n}^{\circ} 19$

159. Ayala Martínez, C., Libro de privilegios..., págs. 364-366, nº 182

16o. Minguella y Arnedo, Toribio, Historia de la diócesis de Sigüenza y de sus obispos, Madrid, Imprenta de la Revista de Archivos, Bibliotecas y Museos, 1910, volumen I, págs. 507-508, nº 145.

161. Alcázar de San Juan según Guerrero VentAS, P., El gran priorato..., pág. 115. En cambio la profesora Grassotti lo identifica con Alija, un castillo situado en el actual término de Talavera la Vieja (Cáceres). GRASSOTTI, Hilda, «Don Rodrigo Ximénez de Rada, gran señor y hombre de negocios en la Castilla del siglo XIII», Cuadernos de Historia de España, 55-56 (1972), p. 173.

162. FITA, Fidel, «La Guardia, villa del partido de Lillo, provincia de Toledo. Datos históricos», Boletín de la Real Academia de la Historia, 11 (1887), pp. 385-388. 
Peñarroya, lo que significaba en el tema que nos ocupa la detracción de un tercio de los diezmos para el arzobispo ${ }^{\mathrm{I} 63}$. El mismo régimen fue extendido a la iglesia de Villar del Pozo después de la adquisición de dicha aldea por el Hospital. En I254 una nueva avenencia sancionó la adscripción de la tercera parte de los diezmos del templo para el prelado toledano y de las otras dos para los freires sanjuanistas ${ }^{164}$.

El panorama que presenta la diócesis de Astorga sobre el tema que nos ocupa es quizá el más peculiar de toda la Corona de Castilla. El acuerdo de I233 nos permite conocer que, si bien en algunas iglesias de la Orden se seguía la norma de entregar un tercio del diezmo al obispo, en muchas le pagaban anualmente una cantidad fija en especie por este concepto o simplemente lo que tenían acostumbrado. La situación era tan enrevesada que el pacto tuvo que revisar de forma particularizada la situación de cada templo sanjuanista ${ }^{165}$.

De todas maneras, y salvando ciertas excepciones locales y de alguna diócesis, el cuadro general parece bastante claro: los hospitalarios solían llevarse dos tercios de los diezmos correspondientes a las parroquias sanjuanistas existentes en el territorio de la Corona de Castilla. No es nada sorprendente, ya que es la proporción usual que correspondía a las órdenes militares ${ }^{166}$. Es previsible que el diezmo significara una de las fuentes de ingresos más importantes para el Hospital. No siempre la Orden de San Juan recaudaba cantidades procedentes de los diezmos en las poblaciones bajo su jurisdicción, pero lo más frecuente era que sí lo hiciera. En este último caso puede que la mayor proporción de la renta señorial procediera de las rentas decimales. Debemos tener en cuenta que el cobro de este valioso tipo de rentas era reservado en principio sólo a señoríos eclesiásticos, lo cual les proporcionaba un carácter más completo y una ventaja inicial sobre los de titularidad laica.

\section{EXENCIONES DE IMPUESTOS REGIOS Y RENTAS INICIALMENTE DE LA MONARQUİA CONCEDIDAS A LA ORDEN.}

Uno de los principales fines de la política señorial sanjuanista parece haber sido la obtención de un control sobre la fiscalidad regia en el interior de sus dominios. Este objetivo se materializó en dos planos diferentes: por un lado, la búsqueda de diferentes exenciones tributarias (lo cual redundaba posteriormente en beneficio de su propia renta), y por otro la absorción directa de determinadas

163. FITA, F., La Guardia..., pp. 388-392.

164. Archivo Histórico Nacional, Códices, 987 B, folios 186v-187r.

165. Ayala Martínez, C., Libro de privilegios..., págs. 459-461, $n^{\circ} 262$.

166. Guadalupe Beraza, María Luisa, Diezmos de la sede toledana y rentas de la mesa arzobispal (Siglo XV), Salamanca, Universidad de Salamanca, 1972, págs. 20-21. LADERo QueSADA, Miguel Ángel y GonZÁLEZ JIMÉnEZ, Manuel, Diezmo eclesiástico y producción de cereales en el reino de Sevilla (1408-1503), Sevilla, Universidad de Sevilla, 1978, pág. 21. 
contribuciones de la monarquía sobre sus señoríos, para poder consolidar así un control exclusivo sobre éstos ${ }^{167}$.

Las exenciones de cargas reales comienzan a conseguirse desde fechas muy tempranas. Algunas de las primeras donaciones obtenidas de la monarquía venían asociadas a ellas. Cuando Alfonso VII dio la villa de Atapuerca al Hospital en II26, lo hizo con exención de fonsadera, anubda, homicidio y cualquier otro gravamen que perteneciera a los derechos reales ${ }^{168}$. El mismo Emperador, al conceder Santa Tevola en Pinario a la Orden en II40 prohibió que los oficiales regios entraran en el lugar para recaudar fonsadera, homicidio, nuncio y mañería ${ }^{169}$. Alfonso VII debió de ser especialmente generoso en esta clase de exenciones. Al donar una plaza junto a Soria en beneficio de los freires sanjuanistas en II52 de nuevo liberó a todos los futuros pobladores de pecho, homicidio, servicio militar y fonsadera ${ }^{170}$.

Los sucesores del Emperador, tanto por la rama leonesa como por la castellana, continuaron concediendo exenciones de derechos reales a algunas propiedades de la Orden. Fernando II así lo hizo con la heredad de Sumen al donarla al Hospital en $\operatorname{II7} 8^{171}$. Alfonso VIII absolvió de todo tributo regio en II9O a las tiendas del Hospital establecidas en Toledo ${ }^{172}$. Alfonso IX prohibió que ninguno de sus representantes exigiera alguna carga a los habitantes de la casa sanjuanista de Mellid en $\mathrm{I}_{2} \mathrm{OI}^{\mathrm{I7}}$. Incluso es probable que el monarca aragonés Pedro Il otorgase una exención general de contribuciones a la encomienda de Molina de Aragón ${ }^{174}$.

Con todo, este tipo de privilegios no llegaron a ser excesivamente numerosos. Su concesión fue puntual y episódica. Hasta es posible que alguno de ellos sea falso, como ocurre con la liberación de derechos reales en favor del monasterio sevillano de San Juan de Acre, presuntamente otorgada por Fernando III en I249 y ratificada por Alfonso X en I26 $^{175}$.

La mayoría de los privilegios del tipo que estamos estudiando emitidos durante el siglo XIll no eran meras gracias de la monarquía, sino que tenían algún motivo muy concreto y explícito. Podía tratarse de una compensación, como pasó en I258 cuando Alfonso X ordenó derribar unas aceñas de la Orden en Toro. Entonces el monarca no sólo autorizó que los hospitalarios adquirieran otra propiedad por un valor equivalente en la misma población, sino que la eximió de contribuciones ${ }^{176}$.

167. BARquero GoÑI, Carlos, «The Hospitallers and Castilian-Leonese Monarchy: the Concession of Royal Rights, Twelfth to Fourteenth Centuries», The Military Orders. Fighting for the Faith and Caring for the Sick, Barber, Malcolm (ed.), Aldershot, Variorum, 1994, pp. 28-33.

168. Delaville Le Roulx, J., Cartulaire..., volumen I, págs. 73-74, $n^{\circ} 78$.

169. Ayala Martínez, C., Libro de privilegios..., págs. 195-196, nº 45.

170. Archivo de la Real Chancillería de Valladolid, Pergaminos, carpeta 107, $n^{\circ} 7$.

171. Archivo Histórico Nacional, Órdenes Militares, Índice 121, folios 17r-18v.

172. Ayala Martínez, C., Libro de privilegios..., págs. 354-355, nº 173.

173. Biblioteca de la Real Academia Española. Manuscrito 384, $n^{\circ} 3$.

174. AguirRe, D., El gran priorato..., págs. 40-41.

175. Carmona Domínguez, José María (ed.), Libro de privilegios de la encomienda de Tocina: 1242-1692, Sevilla, Diputación de Sevilla, 1999, pág. 64, nº 2.

176. Ayala Martínez, C., Libro de privilegios..., pág. 550, nº 335 
La finalidad también podía ser repobladora. En ese caso solía existir siempre algún tipo de limitación del privilegio. Por ejemplo, podía tener un carácter temporal, como la exención de tributos por un plazo de cuatro años obtenida por el gran comendador Fernán Ruíz para los futuros pobladores de la heredad sanjuanista de San Nicolás de Ledesma en I250 ${ }^{177}$. Contamos con un ejemplo en el que la limitación se fijó en el número de beneficiarios: el privilegio otorgado por Alfonso X al convento hospitalario de Santa María del Monte de poder contar con ro vecinos exentos para fundar el lugar llamado la Puebla de Santa María ${ }^{178}$.

El último monarca de nuestro periodo de estudio que eximió de derechos reales a vasallos de un lugar de la Orden fue Sancho IV, quien lo hizo a los vecinos de Tocina en $1284^{179}$.

Este tipo de medidas, de alcance local, resultaban insuficientes para los propósitos de los freires sanjuanistas. De ahí que se esforzaran en conseguir concesiones más generales de la monarquía. Obtuvieron algunas, pero su resultado práctico es bastante discutible. El propio Alfonso VII fue quien tomó las decisiones más favorables en este plano para el Hospital. En II40 ordenó a merinos, jueces y alcaldes que no entraran en las posesiones sanjuanistas por pecho, fonsadera, homicidio o mañería ${ }^{80}$. El mismo monarca amplió considerablemente estas ventajas en II 52. Entonces eximió a los hombres que habitaban en las propiedades hospitalarias de todo servicio o servidumbre ${ }^{\mathrm{r} 8 \mathrm{r}}$. Sin embargo, el privilegio más completo sobre la materia fue el que otorgó el Emperador a la Orden en II56. Consistió en la exención de todo impuesto, carga o prestación del tipo que fuese ${ }^{182}$.

Aparentemente el documento de Alfonso VII de II56 era el definitivo. Sin embargo su eficacia práctica debió de ser limitada, porque los monarcas posteriores continuaron concediendo ventajas fiscales parciales a los freires sanjuanistas. Algunas confusas referencias de documentos que existieron en el antiguo Archivo de Consuegra nos proporcionan pistas sobre ello. Así, es posible que Alfonso VIII confirmara a la Orden en II62 un privilegio en virtud del cual no pagasen acémilas a la monarquía. A cambio de la merced, el Hospital dio al rey tres villas ${ }^{183}$. También puede que Alfonso IX otorgase a los hospitalarios la exención del pago de derechos de portazgo en $\mathrm{I}_{22} 2^{\mathrm{I} 84}$. Precisamente contamos con una información que simultáneamente nos confirma que los miembros de la Orden pretendieron

\footnotetext{
177. Ayala Martínez, C., Libro de privilegios..., págs. 520-521, $\mathrm{n}^{\circ} 311$.

178. AguiRre, D., El gran priorato..., pág. 86.

179. LóPEZ, Tomás, Diccionario Geográfico de Andalucía: Sevilla. Edición preparada por C. Segura Graiño, Sevilla, Diputación de Sevilla, 1989, pág. 152.

180. Rodríguez Campomanes, Pedro, Disertaciones históricas del Orden y Caballería de los Templarios, Barcelona, El Arbil, 1975, págs. 246-247.

181. Archivo Histórico Nacional, Órdenes Militares, carpeta $569, n^{\circ} 35$.

182. Delaville Le RoulX, J., Cartulaire..., volumen I, págs. 186-187, n² 247.

183. Archivo Histórico Nacional, Órdenes Militares, Índice 176, folio $19 r, n^{\circ} 224$.

184. Archivo Histórico Nacional, Órdenes Militares, Índice 176, folio 19v, $n^{\circ} 232$. Posiblemente se corresponda con la más vaga referencia publicada en GUerrero VentAs, Pedro, El Archivo prioral-sanjuanista de Consuegra. Resumen de sus fondos documentales, Toledo, edición del autor, 1985, pág. 101, nº 132.
} 
hacer uso de esta última ventaja y que encontraron problemas para aplicarla en la práctica. En I254 el comendador de Alcántara, ligado a la orden militar del mismo nombre, se quejó a Alfonso X de que los freires del Hospital, entre otras personas, les impedían cobrar portazgo en algunos lugares. Es posible que su comportamiento estuviera motivado por la posesión de los privilegios que acabamos de aludir. Sin embargo, en este caso no se admitió su postura y Alfonso X se inclinó por el respeto a los derechos contrapuestos de la Orden de Alcántara ${ }^{185}$.

El reconocimiento de las inmunidades fiscales de los hospitalarios debía depender de cada coyuntura concreta, pues también contamos con algún ejemplo en el que se reconoció su vigencia. En I246 el merino mayor del rey Fernando III en Galicia, Monio Fernández de Rodero, pretendió entrar en el coto de Gondrame, Friolfe, Vileiriz y Ferreiros para recaudar los impuestos reales. Sin embargo, el comendador y los freires sanjuanistas de Portomarín le enseñaron unas cartas «del rey Fernando y del rey Alfonso su hijo» (quizás unos privilegios de Fernando Il y de Alfonso IX que desconocemos) las cuales demostraban que los hospitalarios poseían todos los derechos reales allí y prohibían la entrada del merino para recaudar impuestos. Monio Fernández así lo reconoció y ordenó a todos sus merinos subordinados que ninguno de ellos exigiera el cobro de tributos en esos $\operatorname{cotos}^{186}$.

Los oficiales de la monarquía no siempre eran tan respetuosos con las exenciones de la Orden. En I265 el gran comendador tuvo que quejarse a Alfonso X porque adelantados y merinos entraban en las villas y lugares del Hospital y recaudaban un tributo, el yantar. El Rey Sabio tuvo que desautorizar a sus representantes y prohibir estos actos a sus adelantados y merinos de León, Galicia y Castilla ${ }^{187}$. La medida no tuvo éxito. Años después la Orden de San Juan hubo de presentar otra protesta formal ante Sancho IV pues el adelantado y los merinos castellanos no sólo cobraban ahora yantar sino también portazgos a los comendadores y vasallos de la Orden. En I294 el monarca mandó poner fin a esas prácticas y reafirmó la vigencia de las órdenes dadas por su padre en $\mathrm{I} 265$ sobre el tema ${ }^{\mathrm{I} 88}$. De todas formas, vistos los antecedentes, albergamos serias dudas de que el mandato de Sancho IV consiguiera ser acatado.

La última medida tomada por la monarquía en apoyo de las exenciones fiscales del Hospital fue la confirmación realizada por Fernando IV en I30o de los privilegios anteriores (cuyo texto desconocemos) que permitían a los vasallos de la Orden no pagar portazgos, ni castillerías, «ni otras cosas» ${ }^{189}$.

185. Ortega y Cotes, Ignacio José, Fernández de Brizuela, José y Ortega Zúñiga y Aranda, Pedro de, Bullarium Ordinis Militiae de Alcantara, olim S. Juliani del Pereiro, Madrid, Tipografía de Antonio Marín, 1759, pág. 69.

186. Delaville Le RoulX, J., Cartulaire..., volumen II, pág. 641, nº 2396.

187. Archivo General de Palacio, Infante don Gabriel, Anexo, legajo 1, $\mathrm{n}^{\circ} 40$ (dirigido al Adelantado y merinos de León y Galicia). Rodríguez Campomanes, P., Disertaciones Históricas..., págs. 247-248 (dirigido al Adelantado y merinos de Castilla).

188. Rodríguez Campomanes, P., Disertaciones históricas..., págs. 247-248.

189. Archivo Histórico Nacional, Órdenes Militares, Índice 176, folio 21r, $n^{\circ} 256$. 
En definitiva, aunque los hospitalarios consiguieron teóricamente liberarse de una buena parte de su carga impositiva, de hecho la proporción de tributos que finalmente tuvieron que pagar tanto ellos como sus vasallos debió de ser mayor de lo que podría hacernos pensar el contenido literal de sus privilegios. De todas maneras, siempre significó por lo menos una rebaja en las cantidades devengadas a la fiscalidad regia que pudo redundar en beneficio de las rentas de la Orden. Sin embargo, quizá lo más interesante de las exenciones fue que constituyeron un primer paso hacia el verdadero objetivo que probablemente buscaba alcanzar la Orden: la apropiación de los tributos reales en el interior de sus dominios.

El inicio de las concesiones regias en esta dirección tiene una cronología bastante más tardía que la de los primeros privilegios de exención tributaria. En II83 Alfonso VIll ya hizo entrega de una regalía reservada en principio a la Corona al incluir en el texto de la donación del castillo de Consuegra a la Orden de San Juan las minas que pudieran hallarse en el término territorial de la fortaleza ${ }^{190}$. El mismo monarca también se desprendió de parte de una renta exclusiva de la monarquía al ceder al comendador consaburense 30 cahíces de sal anuales a partir

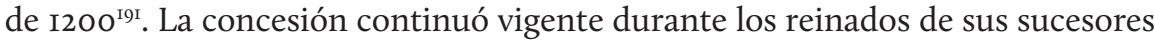
Enrique I y Fernando III ${ }^{192}$. Alfonso VIll también ordenó en su testamento de 1204 que los hospitalarios recibieran anualmente durante diez años dos mil maravedís procedentes de las rentas del rey en Toledo ${ }^{193}$.

Con todo, los primeros pasos en la dirección que más interesaba a la Orden de San Juan tuvieron lugar en el reino de León durante la época de Alfonso IX. En II93 el monarca leonés dejó a la Orden la mitad de lo que recaudase un impuesto directo, el pedido, en las villas hospitalarias de Fresno el Viejo y Paradinas de San Juan ${ }^{194}$. En I224 extendió este régimen a gran parte de las poblaciones dependientes de los freires sanjuanistas en su reino: Fresno el Viejo, Paradinas de San Juan, el valle del Guareña y las villas hospitalarias de toda la Extremadura' ${ }^{195}$. Es probable que el propósito de estas concesiones nos lo descubra un documento de i209. En dicho diploma Alfonso IX declaraba que había dado a los freires del Hospital la mitad de los tributos reales correspondientes a los hombres de la Orden que habitasen en su reino para que esas cantidades se invirtieran en la obra y reparación

190. Guerrero Ventas, P., El gran priorato..., págs. 332-333, nº 4. Sobre la regalía de minas véase LAdero Quesada, Miguel Ángel, Fiscalidad y poder real en Castilla (1252-1369), Madrid, Universidad Complutense, 1993, págs. 100-105.

191. GonZÁLEZ, Julio, El reino de Castilla en la época de Alfonso VIII, Madrid, CSIC, 1960, volumen III, pág. 656, nº 955. La fecha del documento se encuentra en Archivo Histórico Nacional, Órdenes Militares, Índice 121, folio 21r. Sobre la sal como monopolio regio, véase PASTOR de TOGNERI, Reyna, «La sal en Castilla y León. Un problema de la alimentación y del trabajo, y una política fiscal», Cuadernos de Historia de España, $37-38$ (1963), pp. 42-87.

192. Delaville Le Roulx, J., Cartulaire..., volumen II, pág. 178, nº 1447 y GonzÁlez, Julio, Reinado y diplomas de Fernando III, Córdoba, Caja de Ahorros de Córdoba, 1980-1986, volumen II, págs. 80-81, nº 70.

193. FITA, Fidel, «Testamento del rey D. Alfonso VIII (8 diciembre 1204)», Boletín de la Real Academia de la Historia, 8 (1886), pp. 230-238.

194. Ayala Martínez, C., Libro de privilegios..., págs. 361-362, n 179. Sobre el pedido, véase Ladero QueSada, M. A., Fiscalidad y poder..., págs. 53-54.

195. GonzÁLEZ, Julio, Alfonso IX, Madrid, CSIC, 1944, volumen II, págs. 559-560, nº 447. 
de los castillos del valle del Guareña. Al tratarse de una comarca fronteriza con Castilla, tendría sentido que el monarca estuviera interesado en el buen estado de las fortificaciones de la zona. Sin embargo, en esa fecha los freires sanjuanistas ya no consideraban ventajoso el trato y el gran comendador de Hispania consiguió de Alfonso IX su anulación ${ }^{196}$. Muy posiblemente esta decisión conllevase la derogación de la concesión anterior de iI93. A pesar de todo, el Hospital continuaba interesado en la absorción de derechos reales debidos por sus propiedades. Una buena muestra de ello es el hecho de que todavía el propio Alfonso IX diera al prior sanjuanista en I230 el derecho de mañería que detentaba sobre unas heredades que la Orden había adquirido a un caballero llamado Pelayo Yáñez y a su mujer Sancha Gutiérrez ${ }^{197}$.

Durante unos decenios las ambiciones hospitalarias sufren una interrupción. Fernando IIl sólo prometerá durante el cerco de Sevilla en I248 dotar con 3.800 maravedís procedentes de las rentas de la ciudad a los freires sanjuanistas. Sin embargo, también preveía la posibilidad de poder cambiarles dicha cantidad por lugares que tuvieran ese valor ${ }^{198}$. Creemos que fue esto último lo que sucedió, ya que sabemos que tanto Fernando Ill como Alfonso X poco después de la caída de Sevilla concedieron diversas propiedades en la ciudad o en sus cercanías a la Orden $^{199}$.

Hay que esperar al reinado de Alfonso X para que se manifiesten nuevamente los propósitos hospitalarios al respecto. Esto ocurrirá aprovechando que intereses estratégicos impondrán a la monarquía la necesidad de tomar el control de unos castillos sanjuanistas situados cerca de la frontera portuguesa (Moura, Serpa y Mourao). El primer proyecto de permuta redactado en I27I ya contenía la cesión a la Orden de San Juan de varios de los derechos reales recaudados en localidades bajo su señorío o en los que mantenían importantes intereses. Así, el texto preveía la asignación al Hospital del portazgo y todos los derechos que el rey tenía en Quiroga, salvo moneda y prandium, por un valor total de 300 maravedís; las martiniegas y acémilas que se daban al monarca en el valle del Guareña, Fresno el Viejo, Paradinas de San Juan y en las aldeas y lugares vecinos de éstos que pertenecieran a las bailías sanjuanistas, y finalmente una renta de 300 maravedís situada en martiniegas y otros derechos reales de villas y lugares de la Orden donde pareciera más cómodo ${ }^{200}$.

La versión definitiva de la permuta, verificada en I28I, incluyó finalmente el portazgo y todos los otros derechos del rey en Quiroga con excepción de moneda y yantar, las martiniegas y las acémilas que el monarca tenía en el valle del Guareña,

196. Ayala Martínez, C., Libro de privilegios..., pág. 385, nº 201.

197. GonZÁlez, Julio, Alfonso IX, Madrid, CSIC, 1944, volumen II, págs. 714-715, nº 618.

198. Ayala Martínez, C.,, Libro de privilegios..., págs. 508-509, nº 301.

199. GonzÁlezZ, Julio, Repartimiento de Sevilla, Madrid, CSIC, 1951, volumen II, pág. 26. GonzÁlez JıménEZ, Manuel (Ed.), Diplomatario andaluz de Alfonso X, Sevilla, El Monte, 1991, págs. 93-95, $\mathrm{n}^{\circ} 90$.

200. Delaville Le RoulX, J., Cartulaire..., volumen III, págs. 256-257, nº 3.428 . 
en Fresno el Viejo, en Paradinas con sus aldeas y los otros lugares cercanos que pertenecieran a esas bailías hospitalarias, y 300 maravedís situados en la mitad de la martiniega que el rey cobraba a los vasallos de la Orden de las bailías de Puente de Orbigo, Cerecinos de Campos, Santa María de la Horta en Zamora y Vidayanes ${ }^{201}$.

Se han conservado algunas cartas de Alfonso X del año I28I vinculadas a estas concesiones. Gracias a la que envió a los habitantes de Quiroga sabemos que no sólo cedió a los freires sanjuanistas el portazgo y los derechos reales menos yantar y moneda forera, sino también el señorío sobre el lugar ${ }^{202}$. La carta que el monarca mandó por la misma época a los concejos del valle del Guareña, Fresno el Viejo y Paradinas de San Juan, y a todos los otros lugares pertenecientes a estas bailías también nos permite precisar algunos detalles suplementarios. En ella el monarca les comunicaba que había otorgado a la Orden del Hospital las acémilas y la martiniega que dichos concejos le tenían que dar. Por consiguiente les ordenaba que en lo sucesivo cuando él reuniera su ejército o le dieran acémilas en el reino de León, entregaran al prior y freires sanjuanistas las acémilas que estaban forzados a dar al rey en esos casos en lugar de la fonsadera. También les mandaba pagar al Hospital el tributo de la martiniega todos los años. El abono de las citadas contribuciones se haría con el mismo sistema utilizado hasta ese momento: cada uno de los lugares tendría que proporcionar unos jurados a los recaudadores de la Orden que estarían obligados a responder con sus bienes por las cantidades que otros vecinos ocultasen. Existiría un plazo para el pago. Una vez transcurrido éste, si los freires no hubieran recibido las sumas fijadas, sus recaudadores podrían tomar prendas a los habitantes de la población en su lugar ${ }^{203}$.

En realidad, sabemos que la Orden obtuvo cantidades de la martiniega de un número mucho mayor de localidades sanjuanistas que el especificado en el acuerdo de permuta de I28I. En efecto, la confirmación que el infante don Sancho hizo en I283 de las cartas y los privilegios sobre las martiniegas que tenía el Hospital concedidas por Alfonso X por el cambio de Moura, Serpa y Mourao nos informa de que cobraba por este concepto cantidades en Villadecanes, San Martín de Montes, la honor de Villoria, la honor de Villaverde, todos los otros lugares que pertenecían a la bailía sanjuanista de Puente de Orbigo, Morones en la bailía de León, San Vicente de la Lomba, Quintanilla en la bailía de Mayorga, todos las otras localidades dependientes de las bailías de San Juan de Benavente, de Cerecinos de Campos, de Vidayanes, de Santa María de la Horta y de San Gil en Zamora, y de Santa María de la Vega en Toro ${ }^{204}$. Al mismo tiempo, el Infante también ratificó la validez de las cartas y privilegios de su padre resultantes de la permuta sobre la

201. GonzÁlez JIMÉnEZ, M., Diplomatario andaluz..., págs. 502-508, nº 479

202. Rodríguez Campomanes, P., Disertaciones históricas..., págs. 231-232.

203. Ayala Martínez, C., Libro de privilegios..., págs. 576-577, nº 355 .

204. Archivo Histórico Nacional, Órdenes Militares, carpeta 569, n 23. 
martiniega y la fonsadera ${ }^{205}$ de Fresno el Viejo, Paradinas de San Juan, el Valle del Guareña y de todos los otros lugares pertenecientes a esas bailías del Hospital ${ }^{206}$. Finalmente, tras su acceso al trono, don Sancho confirmó el conjunto de toda la operación de permuta, incluyendo las cesiones de rentas reales, en I $285^{207}$.

Con Sancho IV va a proseguir la transmisión a la Orden de San Juan de ciertos derechos de la monarquía sobre sus señoríos, esta vez de manera gratuita. En I285 el rey otorgó a los hospitalarios las acémilas que le habían de dar los vasallos que la Orden tenía en el arzobispado de Toledo. Las unidades administrativas sanjuanistas afectadas por la medida fueron las bailías de Consuegra, Olmos, Peñalver y Alhóndiga. Ningún recaudador regio podría reclamar nada a estos vasallos en las ocasiones en que se exigía este servicio, que era cuando se reunía la hueste real y se reclamaba la prestación del servicio militar. Por el contrario, serían los hombres que el Prior y los freires sanjuanistas establecieran en aquellos lugares quienes lo percibirían ${ }^{208}$.

Dos días después de haber efectuado la concesión, el monarca envió una carta a los vasallos que la Orden del Hospital tenía en las bailías citadas en la que les comunicaba su decisión. Lo más interesante del documento era que Sancho IV reconocía que la prestación de este servicio les eximía del deber de acudir a la hueste regia y del pago de fonsadera. También se anunciaba que en lo sucesivo sería la Orden la que designaría a los recaudadores de los padrones, continuando con el mismo sistema de tributación que se había utilizado hasta ese momento ${ }^{209}$.

Fernando IV confirmó en el año I302 la merced de las acémilas realizada por su padre en $1285^{210}$. Pero la medida más decisiva que tomó este monarca en relación con el tema que ahora estudiamos fue probablemente la cesión al prior de la Orden de San Juan de la mitad de los servicios y ayudas votados por las Cortes que correspondieran a los lugares de la Orden en I295. Conocemos esta información a través de las siempre confusas referencias que los índices del antiguo archivo sanjuanista de Consuegra nos proporcionan de documentos hoy perdidos ${ }^{211}$. Sin embargo, es perfectamente verosímil que sucediera así, puesto que diversas catedrales, monasterios y órdenes militares obtuvieron mercedes similares entre los años I286 y $1334^{212}$. Otro derecho reservado a la monarquía sobre el que los hospitalarios obtuvieron alguna ventaja de Fernando IV fue el de la explotación de las

205. Aparece la fonsadera porque la contribución de las acémilas, como hemos tenido ocasión de comprobar antes, era aquí un sustituto de este tributo. Véanse también las observaciones que hace al respecto LADERO QUESADA, M. A., Fiscalidad y poder..., págs. 46-47.

206. Ayala Martínez, C., Libro de privilegios..., págs.. 585-586, nº 363.

207. Arquivo Nacional da Torre do Tombo, Gaveta 14, maço 1, doc. 9.

208. Archivo General de Palacio, Infante don Gabriel, Anexo, legajo 1, $n^{\circ} 39$.

209. Archivo General de Palacio, Infante don Gabriel, Secretaría, legajo 564, Visitas y Autos, folio 5 r-v.

210. Archivo General de Palacio, Infante don Gabriel, Anexo, legajo 1, $n^{\circ} 39$.

211. Archivo Histórico Nacional, Órdenes Militares, Índice 176 , folio 10v, $n^{\circ} 111$ y folio $20 r, n^{\circ} 238$. Archivo Histórico Nacional, Órdenes Militares, Índice 175, folio 76r, nº 134 y n ${ }^{\circ}$ 136. Guerrero VenTAS, Pedro, El Archivo prioral-sanjuanista de Consuegra. Resumen de sus fondos documentales, Toledo, edición del autor, 1985, pág. 101.

212. Ladero QuesadA, Miguel Ángel, Fiscalidad y poder..., págs. 74, 269-270. 
salinas. Un diploma nos transmite la breve noticia de que este monarca permitió que la Orden de San Juan produjera sal en sus heredades de Salinas de Rosío por algún tiempo hasta I3I2, año en que revocó el privilegio ${ }^{213}$.

El balance final es bastante claro. Los hospitalarios ambicionaban limitar y controlar los impuestos pagados por sus señoríos a la monarquía y consiguieron varios logros en esa dirección. Sin embargo, su éxito fue efímero en la medida que los tributos que efectivamente fueron cedidos a la Orden eran los más tradicionales, cuyo valor efectivo estaba descendiendo mientras que la realeza castellano-leonesa conservó el pleno control sobre las nuevas fórmulas impositivas aparecidas a partir de la segunda mitad del siglo XIII, que eran las más lucrativas ${ }^{214}$. De entre ellas el Hospital sólo obtuvo una participación en los servicios votados por las Cortes ya al final del periodo de nuestro estudio, lo que quizá constituyera la fuente de recursos con más futuro de todas las logradas de la monarquía por la Orden.

\section{INGRESOS PROCEDENTES DEL DOMINIO SOBRE ORGANISMOS CONCEJILES.}

Este último apartado es sobre el que tenemos menos datos. El arrendamiento de cargos municipales debe ser probablemente un fenómeno más tardío. La única posible noticia relacionada que hemos hallado sobre el tema es la protesta del Concejo de Alcázar de San Juan ante el lugarteniente del Maestre de la Orden en el año I308 denunciando que había personas que obtenían los puestos de juez y de alcaldes mediante el pago de dinero. El lugarteniente tuvo que prohibir esta práctica y ordenar que dichos cargos se sortearan anualmente entre los vecinos como estipulaba el fuero de Alcázar²15.

\section{CONCLUSIONES.}

En definitiva, en cuanto a las fórmulas de explotación y rentas que la Orden extraía de sus posesiones, debemos señalar en primer lugar que las evidencias recogidas nos demuestran la persistencia de un dominio directo o, por usar un vocablo del régimen señorial clásico, de una «reserva» de alguna entidad en

213. Castro Garrido, Araceli, Documentación del monasterio de Las Huelgas de Burgos (1307-1321), Burgos, J. M. Garrido Garrido ediciones, 1987, págs. 122-124, nº 252.

214. Ladero Quesada, Miguel Ángel, «Las transformaciones de la fiscalidad regia castellano-leonesa en la segunda mitad del siglo XIII (1252-1312)», en Historia de la Hacienda Española (Épocas Antigua y Medieval). Homenaje al Profesor García de Valdeavellano, Madrid, Instituto de Estudios Fiscales, 1982, págs. 328-368 y 405. Menjot, Dennis, «L'etablissement du systeme fiscal etatique en Castille (1268-1342)», en Génesis medieval del Estado Moderno: Castilla y Navarra (1250-1370), Valladolid, Ámbito, 1987, págs. 149-172.

215. Rubio Herguido, Manuel, «Privilegio otorgado por Frey Arias Gutiérrez Quijada. Año 1308», Noria. Cuadernos de temas alcazareños, 2 (1963), pp. 20-22. 
los señoríos hospitalarios durante los siglos XII y XIIl. Por otra parte, nuestras fuentes evidencian un creciente interés sanjuanista por las rentas derivadas de la administración de justicia. Otra fuente de ingresos para la Orden provenía de la existencia de monopolios señoriales. La gama de censos que el Hospital percibía específicamente como reconocimiento de su señorío podía ser muy extensa. Con todo, la contribución más usual y que prácticamente siempre está presente es la renta que cada poblador pagaba a los freires por la utilización de sus tierras. El peso que suponía dicha renta no parece haber sido excesivo. Sin embargo, como estaba muy extendida por los señoríos de la Orden, probablemente constituiría la segunda mayor fuente de recursos para los hospitalarios, después del diezmo.

La Orden de San Juan también disfrutó del cobro de ciertos tributos indirectos. Las fuentes nos informan de la existencia de dos de ellos, por lo menos: portazgos y montazgos. Las tasas de raíz eclesiástica que la Orden de San Juan obtenía por sus templos eran así mismo muy abundantes. La más importante de ellas era el diezmo. Los hospitalarios generalmente percibían dos tercios de los diezmos provenientes de las parroquias que estaban ligadas a la Orden dentro del territorio de la Corona de Castilla. Es posible que el diezmo fuera uno de los recursos más destacados para el Hospital.

Un objetivo fundamental de la política señorial sanjuanista parece haber sido controlar la fiscalidad regia dentro de sus dominios. Esta finalidad se concreta en dos tipos de actuaciones diferentes. En primer lugar, la obtención de diversas exenciones de tributos. Después, la cesión directa por la monarquía de algunas contribuciones regias en sus señoríos. En ninguno de los dos casos la Orden consiguió cumplir completamente sus propósitos. 


\section{BIBLIOGRAFÍA CITADA}

Aguirre, Domingo, El gran priorato de San Juan de Jerusalén en Consuegra, en I769, Toledo, Instituto Provincial de Investigaciones y Estudios Toledanos, I973.

Alfonso Antón, Isabel, «Renta señorial en la Edad Media de León y Castilla», en Historia de la Hacienda Española (épocas antigua y medieval). Homenaje al profesor García de Valdeavellano, Madrid, Instituto de Estudios Fiscales, I982, pp. 55-65.

Alfonso de SaldaÑa, María Isabel, «Las sernas en León y Castilla. Contribución al estudio de las relaciones socio-económicas en el marco del señorío medieval», Moneda y Crédito, I29 (1974), pp. 153-210.

Ayala Martínez, C. de y otros, «Algunos documentos sobre órdenes militares y fortalezas», Castellum, I (1992), pp. 89-I03.

Ayala Martínez, Carlos de (Compilador), Libro de privilegios de la Orden de San Juan de Jerusalén en Castilla y León (siglos XII-XV), Madrid, Editorial Complutense, I995.

Ayala Martínez, Carlos de, Las Órdenes Militares hispánicas en la Edad Media (siglos XII$X V$ ), Madrid, Marcial Pons, 2003.

BARquero goÑI, Carlos, «Aportación al estudio de la repoblación sanjuanista en la Mancha», Repoblación y reconquista. Actas del III Curso de Cultura Medieval, Aguilar de Campoo, I993, pp. I69-I77.

-, «The Hospitallers and the Castilian-Leonese Monarchy: the Concession of Royal Rights, Twelfth to Fourteenth Centuries», en The Military Orders. Fighting for the Faith and Caring for the Sick, Barber, Malcolm (ed.), Aldershot, Variorum, I994, pp. 28-33.

-, «Los hospitalarios en el reino de León (siglos XII y XIII)», en El reino de León en la Alta Edad Media IX, León, Centro de Estudios e Investigación San Isidoro, I997, pp. 219-634.

-, «Los hospitalarios castellanos y la Mesta: el acuerdo de I434», Espacio, Tiempo y Forma. Serie III. Historia Medieval, I3 (2000), pp. 45-56.

-, Los caballeros hospitalarios durante la Edad Media en España, Burgos, La Olmeda, 2003.

Barrios García, Ángel, Documentación medieval de la Catedral de Avila, Salamanca, Universidad de Salamanca, I98I.

Bonet Donato, María, «Las cartas de población y la renta feudal en el dominio hospitalario del Montsià (s. XIII)», en Miscel.lània en homenatge al P. Agustí Altisent, Tarragona, Diputación de Tarragona, I99I, pp. 55I-57I.

CAlderón Ortega, José Manuel, «Ordenanzas municipales de la villa de Peñalver», Anuario de Estudios Medievales, I8 (I988), pp. 323-327.

Carmona Domínguez, José María (ed.), Libro de privilegios de la encomienda de Tocina: I242-I692, Sevilla, Diputación de Sevilla, I999.

Castro Garrido, Araceli, Documentación del monasterio de Las Huelgas de Burgos (I307I32I), Burgos, J. M. Garrido Garrido ediciones, I987.

Catalina García, Juan, «Carta-puebla de Alhóndiga», Boletín de la Real Academia de la Historia, 35 (I899), pp. 470-476.

Clemente Ramos, Julián, La economía campesina en la Corona de Castilla (I0oo-I30o), Barcelona, Crítica, 2003. 
CoulET, Nicolas, «Les Ordres militaires, la vie rurale et le peuplement dans le sud-est de la France au Moyen Age», Les Ordres militaires, la vie rurale et le peuplement en Europe occidentale (XII ${ }^{-}$XVIII ${ }^{e}$ siècles), Auch, I986, pp. 37-60.

Delaville Le RoulX, Joseph, Cartulaire général de l'Ordre des Hospitaliers de Saint Jean de Jerusalem, IIOO-I3IO, París, Ernest Léroux Éditeur, I894-I906. 4 volúmenes.

DuBY, Georges, «El señorío y la economía campesina. Alpes del Sur, I338», en DuBY, Georges, Hombres y estructuras de la Edad Media, Madrid, Siglo XXI, I977, págs. 79-II9.

Fernández Catón, José María, Colección documental del Archivo de la Catedral de León (775-I230). V (IIO9-II87), León, Centro de Estudios e Investigación San Isidoro, I990.

FERNÁNDEZ Flórez, José Antonio, «El «Becerro de presentaciones» códice I3 del Archivo de la Catedral de León. Un parroquial leonés de los siglos XIII-XV», León y su Historia. Miscelánea Histórica, León, Centro de Estudios e Investigación San Isidoro, I984, volumen $\mathrm{V}$, págs. 263-565.

Fernández Flórez, José Antonio, Colección diplomática del monasterio de Sahagún (857I300). V (I200-I300), León, Centro de Estudios e Investigación San Isidoro, I994.

FiTA, Fidel, «Testamento del rey D. Alfonso VIIl (8 diciembre I204)», Boletín de la Real Academia de la Historia, 8 (I886), pp. 230-238.

FitA, Fidel, «La Guardia, villa del partido de Lillo, provincia de Toledo. Datos históricos», Boletín de la Real Academia de la Historia, II (I887), pp. 373-43I.

Gerbet, Marie-Claude, «Les Ordres Militaires et l'élevage dans l'Espagne médiévale», En la España Medieval V. Estudios en memoria del profesor D. Claudio Sánchez-Albornoz, Madrid, Universidad Complutense, I986, volumen I, págs. 4I3-445.

GonZÁlez, Julio, Alfonso IX, Madrid, CSIC, I944. 2 volúmenes.

-, Repartimiento de Sevilla, Madrid, CSIC, I95I. 2 volúmenes.

-, El reino de Castilla en la época de Alfonso VIII, Madrid, CSIC, I960. 3 volúmenes.

—, Repoblación de Castilla la Nueva, Madrid, Universidad Complutense, I975. 2 volúmenes.

—, Reinado y diplomas de Fernando III, Córdoba, Caja de Ahorros de Córdoba, I980-I986. 3 volúmenes.

GonZÁlez CARballo, José, «Carta-puebla de Lora del Río», Lora del Río. Revista de Estudios Locales, I (I990), pp. I7-34.

GonZÁlez JimÉnez, Manuel (Ed.), Diplomatario andaluz de Alfonso X, Sevilla, Fundación El Monte, I991.

González Mínguez, César, El Portazgo en la Edad Media. Aproximación a su estudio en la Corona de Castilla, Bilbao, Universidad del País Vasco, I989.

Grassott, Hilda, «Don Rodrigo Ximénez de Rada, gran señor y hombre de negocios en la Castilla del siglo XIII», Cuadernos de Historia de España, 55-56 (I972), pp. I-302.

Guadalupe Beraza, María Luisa, Diezmos de la sede toledana y rentas de la mesa arzobispal (Siglo XV), Salamanca, Universidad de Salamanca, 1972.

Guerrero Ventas, Pedro, El gran priorato de la Orden de San Juan de Jerusalén en el Campo de la Mancha, Toledo, Diputación Provincial, I969.

-, El Archivo prioral-sanjuanista de Consuegra. Resumen de sus fondos documentales, Toledo, edición del autor, I985.

KLEıN, Julius, La Mesta. Estudio de la historia económica española. I273-I836, Madrid, Alianza, I979.

Ladero Quesada, Miguel Ángel y González Jiménez, Manuel, Diezmo eclesiástico y producción de cereales en el reino de Sevilla (I408-I503), Sevilla, Universidad de Sevilla, I978.

LADERo Quesada, Miguel Ángel, «Las transformaciones de la fiscalidad regia castellano-leonesa en la segunda mitad del siglo XIII (I252-I3I2)», en Historia de la Hacienda 
Española (Épocas Antigua y Medieval). Homenaje al Profesor García de Valdeavellano, Madrid, Instituto de Estudios Fiscales, I982, pp. 319-406.

-, «Comentario sobre los señoríos de las órdenes militares de Santiago y Calatrava en Castilla la Nueva y Extremadura a fines de la época medieval», Las órdenes militares en el Mediterráneo occidental. Siglos XIII-XVIII, Madrid, I989, pp. I69-I8o.

—, Fiscalidad y poder real en Castilla (I252-I369), Madrid, Universidad Complutense, I 993.

LERA Maíllo, José Carlos de y otros, Colección diplomática del imperial monasterio de Nuestra Señora de Valparaíso (II43-I499), Zamora, Instituto de Estudios Zamoranos Florián de Ocampo, I998.

Lomax, Derek W., La Orden de Santiago (II70-I275), Madrid, CSIC, I965.

López, Tomás, Diccionario Geográfico de Andalucía: Sevilla. Edición preparada por C. Segura Graiño, Sevilla, Diputación de Sevilla, I989.

Martín, José Luis, «Diezmos eclesiásticos. Notas sobre la economía de la sede zamorana (s. XII-XIII)», Actas de las I Jornadas de Metodología aplicada de las Ciencias Históricas. II Historia Medieval, Santiago de Compostela, I975, pp. 69-78.

-, Documentos Zamoranos. I. Documentos del Archivo Catedralicio de Zamora. Primera Parte (II28-I26I), Salamanca, Universidad de Salamanca, I982.

Martín Martín, José Luis y otros, Documentos de los Archivos Catedralicio y Diocesano de Salamanca (siglos XII-XIII), Salamanca, Universidad de Salamanca, I977.

Martínez Díez, Gonzalo, Libro Becerro de las Behetrías. Estudio y texto crítico, León, Centro de Estudios e Investigación San Isidoro, I98I. 3 volúmenes.

-, «Estructura administrativa local en el naciente reino de Toledo», Estudios sobre Alfonso VI y la reconquista de Toledo. Actas del II Congreso Internacional de Estudios Mozárabes, Toledo, I988, pp. 43-I62.

-, Fueros locales en el territorio de la provincia de Burgos, Burgos, Institución Fernán González, I982.

Menjot, Dennis, «L'etablissement du systeme fiscal etatique en Castille (I268-I342)», en Génesis medieval del Estado Moderno: Castilla y Navarra (I250-I37O), Valladolid, Ámbito, I987, págs. I49-I72.

Minguella Y ARnedo, Toribio, Historia de la diócesis de Sigüenza y de sus obispos, Madrid, Imprenta de la Revista de Archivos, Bibliotecas y Museos, I9IO. 3 volúmenes.

Moreta Velayos, Salustiano, Rentas monásticas en Castilla: problemas de método, Salamanca, Universidad de Salamanca, I974.

Moxó, Salvador de, «Los señoríos: cuestiones metodológicas que plantea su estudio», Anuario de Historia del Derecho Español, 43 (1973), pp. 27I-309.

-, «Los señoríos. Estudio metodológico», en Actas de las I Jornadas de Metodología Aplicada de las Ciencias Históricas. II Historia Medieval, Santiago de Compostela, I975, pp. I63-173.

-, Feudalismo, señorío y nobleza en la Castilla medieval, Madrid, Real Academia de la Historia, 2000.

Novoa Portela, Feliciano, La Orden de Alcántara y Extremadura (siglos XII-XIV), Mérida, Editora Regional de Extremadura, 2000.

Ortega y Cotes, Ignacio José, Fernández de Brizuela, José y Ortega Zúñiga y AranDA, Pedro de, Bullarium Ordinis Militiae de Alcantara, olim S. Juliani del Pereiro, Madrid, Tipografía de Antonio Marín, I759.

Ortega y Cotes, Ignacio José, Álvarez de Baquedano, Juan Francisco, y Ortega ZúÑiga y Aranda, Pedro de, Bullarium Ordinis Militiae de Calatrava, Barcelona, El Albir, I98I.

PASTOR de TOGneri, Reyna, «La sal en Castilla y León. Un problema de la alimentación y del trabajo, y una política fiscal», Cuadernos de Historia de España, 37-38 (1963), pp. 42-87. 
Peinado Santaella, Rafael G., «Estructura de la renta feudal en los señoríos andaluces de la Orden de Santiago a finales de la Edad Media. I Encomiendas orientales», en Actas I Coloquio de Historia de Andalucía. Andalucía Medieval, Córdoba, I982, pp. 47I-507.

-, «La renta señorial en las órdenes militares de la Corona de Castilla durante la baja Edad Media», Historia, Instituciones, Documentos, I8 (I99I), pp. 403-424.

Porras Arboledas, Pedro Andrés, Los señoríos de la Orden de Santiago en su provincia de Castilla durante el siglo XV, Madrid, Universidad Complutense, I98I, 2 volúmenes.

—, La Orden de Santiago en el siglo XV. La provincia de Castilla, Madrid, Dykinson, I997.

—, «Los portazgos en León y Castilla durante la Edad Media. Política real y circuitos comerciales», En la España Medieval, I5 (I992), pp. I6I-2II.

Procter, Evelyn S., Curia y Cortes en Castilla y León, I072-I295, Madrid, Cátedra, I988.

Ramos de CAStro, Guadalupe, El arte románico en la provincia de Zamora, Zamora, Diputación de Zamora, I977.

Rodríguez Blanco, Daniel, La Orden de Santiago en Extremadura en la Baja Edad Media (siglos XIV y XV), Badajoz, Diputación Provincial de Badajoz, I985.

Rodríguez Campomanes, Pedro, Disertaciones históricas del Orden y Caballería de los Templarios, Barcelona, El Albir, I975.

Rodríguez Díez, Matías, Historia de la ciudad de Astorga, $2^{\text {a }}$ edición, Astorga, Porfirio López, I909.

Rodríguez-Picavea Matilla, Enrique, «Las órdenes militares en la diócesis de León: el Becerro de presentaciones», Congreso de Jóvenes Historiadores y Geógrafos. Actas, Madrid, I990, volumen I, pp. 609-7I2.

-, Las Órdenes Militares y la frontera. La contribución de las Órdenes a la delimitación de la jurisdicción territorial de Castilla en el siglo XII, Madrid, Universidad Autónoma de Madrid, I994.

-, La formación del feudalismo en la meseta meridional castellana. Los señoríos de la Orden de Calatrava en los siglos XII-XIII, Madrid, Siglo XXI, I994.

-, «La Orden de San Juan en la frontera castellano-andalusí del siglo XII», Actas del Primer Simposio Histórico de la Orden de San Juan en España, Toledo, 2003, pp. I2I-I42.

-, Los monjes guerreros en los reinos hispánicos. Las Órdenes Militares en la Península Ibérica durante la Edad Media, Madrid, La Esfera de los Libros, 2008.

Romaní Martínez, Miguel, A Colección Diplomática do Mosteiro Cisterciense de Santa María de Oseira (Ourense) (IO25-I3IO), Santiago, Tórculo, I989. 2 volúmenes.

Rubio Herguido, Manuel, «El escudo de Alcázar», Noria. Cuadernos de temas alcazareños, I (I962), pp. 5-II.

—, «Privilegio otorgado por Frey Arias Gutiérrez Quijada. Año I308», Noria. Cuadernos de temas alcazareños, 2 (1963), pp. 15-23.

Ruiz Asencio, José Manuel, Colección documental del Archivo de la Catedral de León VIII (I230-I269), León, Centro de Estudios e Investigación San Isidoro, I993.

Serra Ruiz, Rafael, «La Orden de San Juan de Jerusalén en el reino de Murcia (siglo XIII)», Anuario de Historia del Derecho Español, 38 (i968), pp. 553-590.

SolAno, Emma, La Orden de Calatrava en el siglo XV. Los señoríos castellanos de la Orden al fin de la Edad Media, Sevilla, Universidad de Sevilla, I978. 
Calidad de Revistas

científicas Españolas

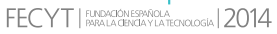

SERIE III HISTORIA MEDIEVAL

REVISTA DE LA FACULTAD DE GEOGRAFİA E HISTORIA
AÑO 2016

ISSN: 0214-9745

E-ISSN 2340-1362

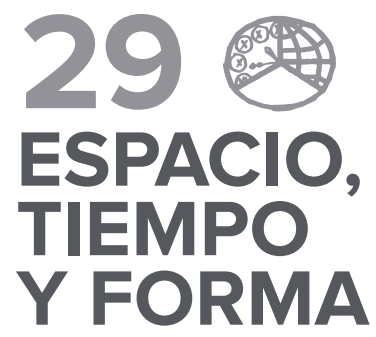

\section{Artículos}

17 Leticia Agúndez San Miguel

El tumbo de San Pedro de Montes como instrumento de recreación de la memoria instituciona

\section{Roberto Antuña Castro}

La copia de escrituras públicas a la muerte del notario titular

75 Carlos de Ayala Martínez

Alfonso VIII, Cruzada y Cristiandad

\section{Carlos Barquero Goñ I}

La renta señorial de la Orden de San Juan en Castilla durante los siglos XII y XIII

\section{MARgARITA CABRERA SÁNCHEZ}

Cristianos nuevos y cargos concejiles. Jurados conversos en Córdoba a fines del Medievo

183 Francisco de Paula Cañas Gálvez

La correspondencia de Leonor de Alburquerque con su hijo Alfonso $V$ de Aragón: acción política y confidencia familiar del partido aragonés en la corte de Castilla (1417-1419)

\subsection{Octavio Colombo} del siglo XV

os dueños del dinero. Prestamistas abulenses a mediados

\section{Alfonso Domínguez de LA CONCHA \\ Apropiaciones de comunales en la Puebla de Guadalupe} (Cáceres) durante la Baja Edad Media

\section{Antonio Vicente Frey SÁnChez}

Sobre la articulación administrativa de la cuenca del río Segura entre los siglos VII y VIII: algunos recientes elementos para identificar una frontera «blanda»

\section{David Gallego VALLE}

La fortificación medieval en el Campo de Montiel (ss. VIII-XVI). Análisis de su secuencia histórica y constructiva

\section{MAURICIO HERRERO JIMÉNEZ}

El cuidado del alma y otros cuidados en las cartas de aniversario del cabildo de los clérigos de Cuéllar en el siglo XIV
4.01 JaIME DE HOZ OnRUBIA

Antroponimia y reconstrucción histórica: consideraciones sobre la identificación personal en el paso de la Edad Media a la Moderna en la Corona de Castilla

\section{Carmen López Martínez \\ Sancho IV de Castilla y la imposición del diezmo mudéjar} en Murcia

\subsection{PABlo Martín Prieto} el valor de los preámbulos

Idea e imagen del rey en la diplomática medieval hispana:

\section{Luis Martínez García}

Los campesinos al servicio del señor, según los fueros locales burgaleses de los siglos XI-XIII

54.3 Juan José Morales Gómez

Las minas de alumbre del bajo jiloca (Zaragoza) y su explotación a fines de la Edad Media

571 DAVID D. NAVARRO

Precisiones literarias sobre el antijudaísmo de Gonzalo de Berceo en el Milagro de Teófilo (XXIV)

593 JaIME PIQUeras JuAN

Matrimonios en régimen de germania y relaciones intrafamiliares en Alicante durante el siglo XV

621 Aída PORTILLA GonzÁlez

El arte del buen morir en los testamentos medievales de la catedral de Sigüenza (siglos XIII-XV)

675 María Del Pilar RÁbade Obradó

Justas, fiestas y protagonismos: Alegrías y placeres en El Victorial de Gutierre Díaz de Games

699 TERESA SÁnchez ColladA

La dote matrimonial en el Derecho castellano de la Baja Edad Media. Los protocolos notariales del Archivo Histórico Provincial de Cuenca (1504-1507)

\section{Casto Manuel Solera Campos}

Pureza y continencia durante la Edad Media: la castidad conyugal en la Orden de Santiago (siglos XII-XVI)

\section{7 ÓsCAR VILLARROEL GONZÁlEZ}

Autoridad, legitimidad y honor en la diplomacia: los conflictos anglo-castellanos en los concilios del siglo XV

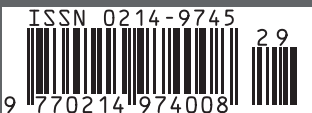




\section{9}

\section{ESPACIO,}

\section{TIEMPO}

Y FORMA

UกED

SERIE III HISTORIA MEDIEVAL

REVISTA DE LA FACULTAD DE GEOGRAFİA E HISTORIA

\section{Libros}

817 Álvarez Fernández, María y Beltrán SuÁrez, Soledad, Vivienda, gestión y mercado inmobiliarios en Oviedo en el tránsito de la Edad Media a la modernidad. El patrimonio urbano del cabildo catedralicio (RobERTO J. GONZÁlez ZALACAín)

821 BeCEIro PITA, Isabel (dir.), Poder, piedad y devoción. Castilla y su entorno, siglos XII-XV (ANA ECheVARría ARSUAGA)

825 García Fernández, Ernesto (Coord.), Laguardia y sus fueros. Estudios Históricos realizados en conmemoración del 850 aniversario de la concesión de la carta fundacional (ANA MARÍA RIVERA MEDINA)

829 García Fernández, Ernesto y Bonachía Hernando, Juan Antonio (eds.), Hacienda, mercado y poder al Norte de la Corona de Castilla en el tránsito del Medievo a la Modernidad (AnA María Rivera Medina)

843 Martín Prieto, Pablo, Las matemáticas en la Edad Media: una historia de las matemáticas en la Edad Media occidental (ANTONIO HERNANDO Esteban)

847 Miranda García, Fermín, Breve Historia de los Godos (Ana María JIMÉNEZ GARNICA)

851 Moreno Ollero, Antonio, Los dominios señoriales de la Casa de Velasco en la Baja Edad Media (DIEGo ARSUAGA LABORDE)

855 ORTEgo Rico, Pablo, Poder financiero y gestión tributaria en Castilla: Los agentes fiscales en Toledo y su reino (1429-1504) (Ana María Rivera Medina)

861 Solórzano Telechea, Jesús A. \& Arízaga bolumburu, Beatriz \& AgUiAR ANDRADE, Amélia (editores), Ser mujer en la ciudad medieval eUrOPEa (MARIANA ZAPATERO)

869 Solórzano Telechea, Jesús A. \& Arízaga bolumburu, Beatriz \& Sicking, Louis (eds.), Diplomacia y comercio en la Europa Atlántica Medieval (Roberto J. GonzÁlez ZaLACAín)

875 VÍtORES CASADO, Imanol \& GoICOLEA JULIÁN, Francisco Javier \& ANGULO Morales, Alberto \& Aragón RuAno, Álvaro (edición y estudios), Hacienda, fiscalidad y agentes económicos en la Cornisa Cantábrica y su entorno (1450-1550). Nuevos textos para su estudio (ENRIQUE CANTERA MONTENEGRO) 